\title{
Computer Aided Design of Langasite resonant cantilevers: Analytical models and simulations
}

\author{
C.R. Tellier ${ }^{1 *}$, T.G. Leblois ${ }^{2}$, S. Durand ${ }^{3}$ \\ ${ }^{1}$ Frequency and Time Dept., FEMTO-ST Institute, 26 chemin de l'épitaphe, \\ 25030 Besançon Cedex, France \\ E-mail: ctellier@ens2m.fr \\ ${ }^{2}$ MN2S Dept., FEMTO-ST Institute, 32 avenue de l'Observatoire, 25044 \\ Besançon Cedex, France \\ ${ }^{3}$ LAUM, rue Aristote, 72085 Le Mans Cedex 9, France
}

PACS : 85.85.+j, 81.05.Zx

Keywords : Langasite, Resonant cantilever, Wet micromachining, Simulator, FEM analysis

Shortened version of the title: CAD of LGS resonant cantilevers

* Corresponding author, Tel: + 333814028 30, fax: + 333818857 14, E-mail address: ctellier@ens2m.fr 


\begin{abstract}
Analytical models for the piezoelectric excitation and for the wet micromachining of resonant cantilevers are proposed. Firstly, computations of metrological performances of micro-resonators allow us to select special cuts and special alignment of the cantilevers. Secondly the self-elaborated simulator TENSOSIM based on the kinematic and tensorial model furnishes etching shapes of cantilevers. As the result the number of selected cuts is reduced. Finally the simulator COMSOL $\AA$ is used to evaluate the influence of final etching shape on metrological performances and especially on the resonance frequency. Changes in frequency are evaluated and deviating behaviours of structures with less favourable built-ins are tested showing that the $\mathrm{X}$ cut is the best cut for LGS resonant cantilevers vibrating in flexural modes (type 1 and type 2) or in torsion mode.
\end{abstract}




\section{INTRODUCTION}

Piezoelectric devices are highly attractive for resonators $[1,2]$ and for sensors applications [27] and up to now the quartz crystal remains the reference material for bulk acoustic wave (BAW) resonators with high stability. Moreover quartz resonant structures can be fabricated by wet micromachining [7-9]. The potential MEMS applications of quartz still simulate the development of quartz microsensors [6-8]. Vibratory gyroscopes constitute a good example of combined piezoelectric excitation and MEMS technology based on quartz crystal.

However in the last decade the langasite (LGS) crystal has attracted attention for sensors operating at elevated temperature [10-12] because this crystal possesses high piezoelectric coupling, temperature stability and low acoustic loss [13]. LGS sensors and especially microbalances and nanobalances [10,11] are based on BAW resonators vibrating in a thickness shear mode. More recently E. Ansorge et $A l[13,14]$ investigated the possibility to design and to fabricate cantilever beams in Y-cut LGS. These workers fabricated beams with length varying from $1.35 \mathrm{~mm}$ to $4.4 \mathrm{~mm}$ by chemical etching. Effectively until 2002 the chemical etching of LGS has been primarily limited to chemical polishing of LGS plates [1618]. The possible anisotropy of the dissolution of LGS crystal in acidic solutions has not been discussed. Fortunately in the past few years the selective etching of the LGS crystal in various etchants has been studied [19-21] showing that LGS can be also considered as a promising material for MEMS. The aim of this work is thus to design new LGS sensors that fulfill the following requirements

(i) Operation of resonant cantilevers with flexion or torsion modes.

(ii) Microfabrication of the resonant structure by wet micromachining which is a low cost batch process.

Cubes from LGS ingots are frequently fabricated with faces perpendicular to the $\mathrm{X}$ and $\mathrm{Y}$ crystal axes. The easily available faces are thus the $\mathrm{X}$ and $\mathrm{Y}$ faces and the $\mathrm{X}$ cut and the $\mathrm{Y}$ cut can be qualified of commercial cuts. It is the reason why this study is concerned with these two commercial cuts. The first part of this paper deals with the piezoelectric effect of LGS and with computations of resonance frequency. As a main result we retain several possibilities for cantilevers vibrating in flexion or in torsion modes. The second part is devoted to the numerical simulation of 3D etching shapes for LGS cantilevers micromachined in a $\mathrm{HCl}$ solution. In this part a special attention is paid to the final 3D etching shape that depending on orientation deviates more and less from the optimum shape. A final selection of cuts and cantilever alignments is carried out by combining results of parts 1 and 2. A FEM analysis of theoretical micromachined structures is performed in part 3 for the selected orientations. This analysis confirms that requirements (i) and (ii) may be met for commercial cuts.

\section{PIEZOELECTRIC EXCITATION}

Let be $x_{1}$ and $x_{3}$ the rotated axes corresponding to a doubly rotated LGS plate (Fig. 1) whose orientation is defined by means of two angles of cuts $(\varphi, \theta)$ according to the IEEE Standard on piezoelectricity [22]. Adopting this standard gives the angles of cut listed in table 1 for the $\mathrm{X}$ and $\mathrm{Y}$ cuts that can be considered as "commercial" cuts.

To optimize the metrological performance of a resonant cantilever it is necessary to align the cantilever along a specific direction $\mathrm{x}^{\prime}{ }_{1}$. Hence the final system coordinates $\left(\mathrm{x}_{1}{ }_{1}, \mathrm{x}_{2}{ }_{2}, \mathrm{x}_{3}{ }_{3}\right)$ is obtained by a third rotation of $\Psi$ degrees about the $x_{2}^{*}$ axis (Fig 1b). This section that is concerned with flexural and torsional modes of vibration is divided into two parts:

(1) The first part focuses on piezoelectric coefficients in order to determine orientations and cantilever alignments that give the best piezoelectric excitation for the two modes. 
(2) In the second part an analytical model is used to compute the resonance frequencies of flexural and torsion vibration modes.

For convenience in the following the modeling for each mode of vibration is treated separately.

For piezoelectric excitation of a cantilever vibrating in a flexural mode in the plane ( $\mathrm{x}_{1}{ }_{1}$, $\mathrm{x}_{2}{ }_{2}$ ) or in a torsion mode about the $\mathrm{x}_{1}{ }_{1}$ axis two electrode configurations may be used (Fig. 2):

(A) The configuration $A$ in which two pairs of electrodes at excitation voltages $+V_{o}$ and $-\mathrm{V}_{\mathrm{o}}$ are placed on the upper and lower faces of the cantilever (Fig. 2a)

(B) The configuration B requires four electrodes. The two narrow electrodes deposited on lateral faces are driven by a voltage $-V_{o}$ whereas an excitation voltage $+V_{o}$ is applied to the two wider electrodes on upper and lower faces. (Fig. 2c).

Figures $2 b$ and $2 d$ present schematically the lines of the electric field for the configurations $\mathrm{A}$ and $\mathrm{B}$ that confine the electric field $\mathrm{E}$ in the cross-sectional $\left(\mathrm{x}_{2}{ }_{2}, \mathrm{x}_{3}\right)$ plane. It follows the absence of the longitudinal component $\mathrm{E}_{1}{ }_{1}$ of the electric field.

Let us recall that the modeling can begin with the constitutive equation for the converse piezoelectric effect [1] that assumes that strain $S_{\mathrm{m}}$ depends linearly on the electric field $\mathbf{E}$. Equation (1) is written using the matrix notation:

$$
\mathrm{S}_{\mathrm{m}}=\mathrm{d}_{\mathrm{im}} \mathrm{E}_{\mathrm{i}}
$$

There is only five non zero piezoelectric constants:

$$
\mathrm{d}_{11} ; \mathrm{d}_{12}=-\mathrm{d}_{11} ; \mathrm{d}_{14} ; \mathrm{d}_{25}=-\mathrm{d}_{14} ; \mathrm{d}_{26}=-2 \mathrm{~d}_{11}
$$

Sets of material constants have been reported in literature by several authors [23-28]. Among these sets we have retained for the independent piezoelectric constants $d_{11}$ and $d_{14}$ the values published recently by Malocha [24, 25, 27], i.e.

$$
\mathrm{d}_{11}=6.15 \mathrm{pC} / \mathrm{N}, \quad \mathrm{d}_{14}=-6.01 \mathrm{pC} / \mathrm{N}
$$

When we are concerned with the Cartesian system $\left(\mathrm{x}_{1}, \mathrm{x}_{2}{ }_{2}, \mathrm{x}_{3}\right)$ Eq. (1) takes the general form

$$
\mathrm{S}_{\mathrm{m}}^{\prime}=\mathrm{d}_{\mathrm{im}}^{\prime} \mathrm{E}_{\mathrm{i}}^{\prime}
$$

where the primed piezoelectric constants $\mathrm{d}_{\mathrm{ijk}}$ obey to the usual tensor transformation rule that involves the direction cosines $\alpha_{\mathrm{ij}}$ of the rotated axis [1].

\subsection{Piezoelectric constants for flexural modes of vibration}

For the flexural mode if we take into account the electric field property it is clear that Eq.3 becomes

$$
\mathrm{S}_{1}^{\prime}=\mathrm{d}_{21}^{\prime} \mathrm{E}_{2}^{\prime}+\mathrm{d}_{31}^{\prime} \mathrm{E}_{3}^{\prime}
$$

At this point it is important to recall that the distributions of the electric field as viewed in 
Fig. 2 show changes in components $\mathrm{E}_{2}{ }_{2}$ and $\mathrm{E}_{3}{ }_{3}$ with corresponding Cartesian coordinates $\mathrm{x}_{2}$ and $x^{\prime}{ }_{3}$. Hence in most cases we observe inevitably a dependence of strain $\mathrm{S}_{1}{ }_{1}$ with these two coordinates that induces a coupling between two flexural modes. It is imperative that the strain $\mathrm{S}_{1}{ }_{1}$ depends only on a component $\mathrm{E}_{\mathrm{i}}$. The solution to obtain a pure flexural mode is thus trivial and consists to select orientation $(\varphi, \theta)$ and alignment $(\psi)$ for which one of the $d^{\prime}{ }_{i 1}$ coefficients involved in Eq. 4 is equal to zero.

Let us firstly consider the electrode configuration A. To have a pure flexion mode in the $\left(\mathrm{x}_{1}, \mathrm{x}_{2}{ }_{2}\right)$ plane (Fig. 3a , flexion type 1) described by

$$
\mathrm{S}_{1}^{\prime}=\mathrm{d}_{31}^{\prime} \mathrm{E}_{3}^{\prime}
$$

we select orientations and alignments that obey at the following selection rule:

(R1) High primed piezoelectric coefficient d' ${ }_{31}$ and zero d' 21

Conversely according to

$$
\mathrm{S}_{1}^{\prime}=\mathrm{d}_{21}^{\prime} \mathrm{E}_{2}^{\prime}
$$

a pure flexion in the $\left(\mathrm{x}_{1}{ }_{1}, \mathrm{x}_{3}\right)$ plane (flexion of type 2 , Fig. $3 \mathrm{~b}$ ) is generated if $\mathrm{d}^{\prime}{ }_{31}$ is zero a condition that ensures the absence of action of $\mathrm{E}_{3}{ }_{3}$ on $\mathrm{S}_{1}{ }_{1}$. This leads to the selection rule:

(R2) High primed piezoelectric coefficient d' ${ }_{21}$ and zero d' ${ }_{31}$

If we turn attention to the electrode configuration B it appears that a pure flexion of type 1 (type 2 ) occurs if the generation of $\mathrm{S}_{1}{ }_{1}$ is due to component $\mathrm{E}_{2}{ }_{2}\left(\mathrm{E}_{3}{ }_{3}\right)$ alone. Consequently the foregoing selection rules R1 and R2 must be inverted.

The aim of this paper is to explore commercial LGS cuts. Among the commercial X, Y and $\mathrm{Z}$ cuts only the $\mathrm{X}$ and $\mathrm{Y}$ cuts may be excited piezoelectrically. The selection of alignments for the two electrode configurations is facilitated by using a graphical representation of $\mathrm{d}{ }_{\mathrm{i} 1}$ that consists of polar plots. The primed piezoelectric constants are thus computed to draw the polar plots of Fig. 4. At this point it should be mentioned that the graph of d' ${ }_{31}$ is absent in the case of the $X$ cut. Effectively taking into account the zero values of constant $d_{3 m}$ and of direction cosines $\alpha_{31}$ and $\alpha_{11}$ we readily find that the primed coefficient $d^{\prime}{ }_{31}$ is equal to zero whatever the alignment.

For technology reasons a flexion of type 1 is frequently activated. This means that rules R1 and R2 must be satisfied for configurations A and B respectively. Nevertheless possible selections for a flexural mode of type 2 are also examined. Careful analysis of the polar plots call for several remarks:

(1) In the case of the cut $\mathrm{X}$ it appears that $\mathrm{d}_{21}$ passes through a small maximum for alignments $\psi=135^{\circ}$ and $\psi=315^{\circ}$ and that this primed coefficient takes enough high value (about $\left.6.1510^{-12} \mathrm{~V} / \mathrm{m}\right)$ for cantilevers aligned along the $\mathrm{Y}$ axis $\left(\psi=0^{\circ}\right.$ or $\left.\psi=180^{\circ}\right)$. Taking into account that coefficient $\mathrm{d}_{31}$ is equal to zero for any alignment into the $\mathrm{X}$ plane it readily appears that a flexion of type 1 (type 2) may be activated with the electrode configuration $\mathrm{B}$ (A).

(2) The Y cut seems inappropriate to design resonant cantilevers vibrating in a flexural mode. Both primed $d^{\prime}{ }_{21}$ and $d^{\prime}{ }_{31}$ coefficients exhibit relatively high values for $\psi$ in the range 
$\left(30^{\circ}, 60^{\circ}\right)$ and the three other associated ranges. Consequently it is impossible to verify the foregoing selection rules.

So if we limit our investigation to commercial cuts solutions for pure flexural modes are only for the $\mathrm{X}$ cut. Table 2 summarizes the final selection and gives values of the primed coefficient $\mathrm{d}_{21}$.

\subsection{Piezoelectric constants for torsion modes of vibration}

With a Cartesian system of arbitrary orientation and with non-zero shear coefficients $\mathrm{d}^{\prime}$ im torsion vibrations can be activated. For torsion modes about the longitudinal $\mathrm{x}_{1}{ }_{1}$ axis the resulting shear strains $\mathrm{S}_{5}{ }_{5}$ and $\mathrm{S}_{6}{ }_{6}$ may be affected by electric field's $\mathrm{x}{ }_{2}$ - and $\mathrm{x}{ }_{3}$ - components:

$$
\left\{\begin{array}{l}
\mathrm{S}_{5}^{\prime}=\mathrm{d}_{25}^{\prime} \mathrm{E}_{2}^{\prime}+\mathrm{d}_{35}^{\prime} \mathrm{E}_{3}^{\prime} \\
\mathrm{S}_{6}^{\prime}=\mathrm{d}_{26}^{\prime} \mathrm{E}_{2}^{\prime}+\mathrm{d}_{36}^{\prime} \mathrm{E}_{3}^{\prime}
\end{array}\right.
$$

Here again coupling between torsion modes are unwanted. The way to observe pure torsion modes is to search orientations that obey to the selection rules:

(R3) High values for pairs of primed piezoelectric coefficients $\left(d^{\prime}{ }_{26}, d^{\prime}{ }_{35}\right)$ together with zero values for the $\left(\mathrm{d}_{25}, \mathrm{~d}^{\prime}{ }_{36}\right)$ pair.

(R4) This rule is simply obtained by inverting the conditions established for rule R3.

From Fig. 2 rules R3 and R4 are valid for configurations A and B respectively. Figure 5 gives polar plots of primed "shear" coefficients for standard X and Y cuts. For the X cut the primed coefficient $\mathrm{d}_{26}$ is zero for all possible alignments. Hence it is impossible to active a torsion mode with the configuration $\mathrm{A}$. $\mathrm{X}$ and $\mathrm{Y}$ cuts have potential advantages for cantilever vibrating in torsion modes because:

(i) An Y cantilever aligned along the $\mathrm{x}_{3}{ }_{3}$ axis $\left(\psi=90^{\circ}\right)$ that is to say along the so-called $\mathrm{Z}$ axis can vibrate on a perfect torsion mode using the electrode configuration $\mathrm{B}$. Effectively we have zero d' ${ }_{26}$ and $\mathrm{d}_{35}, \mathrm{~d}_{31}$ and $\mathrm{d}_{21}$ for this special alignment.

(ii) With the configuration $\mathrm{B}$ and an alignment at $45^{\circ}$ from the $\mathrm{x}^{*}{ }_{1}$ axis (crystallographic $\mathrm{X}$ direction for an $\mathrm{Y}$ cut) or from the $\mathrm{x}_{3}{ }_{3}$ axis an $\mathrm{Y}$ cantilever can be satisfactory activated on a torsion mode because $\mathrm{d}_{25}$ is zero and $\mathrm{d}^{\prime}{ }_{36}, \mathrm{~d}^{\prime}{ }_{31}, \mathrm{~d}^{\prime}{ }_{21}$ are small whereas the two other shear coefficients are high.

(iii) A pure torsion mode can be accomplished with an $\mathrm{X}$ cut and the electrode configuration $\mathrm{B}$ for an alignment along the $\mathrm{x}_{3}$ axis.

For the selected orientations and alignments the primed coefficients are listed in Table 3.

Once the selection of special orientations finished it is necessary for the operating conditions established in Tables 2 and 3 to determine the resonance frequency. This is done in the following section. 


\section{RESONANCE FREQUENCY.}

\subsection{Flexural vibration modes}

Let us consider a cantilever which geometry is given by $\ell$ for the length, $d$ for the thickness and $\mathrm{w}$ for the width. We suppose that the length $\ell$ of the cantilever is markedly larger than cross section dimensions $d$ and $w$. The conditions of validity of the Bernouilli-Euler model [1, 29 ] are thus respected. Let us consider a flexion of type 1. Calculations of the resonance frequency are performed in the framework of this model and involve [31]:

i) The fundamental equation of the dynamics that here is applied to a narrow slice of the beam of length $\Delta \mathrm{x}^{\prime}{ }_{1}$ and mass $\Delta \mathrm{m}$

ii) The equation that express the equilibrium of moments $\mathrm{M}_{\mathrm{x}^{\prime} 3}$ about the $\mathrm{x}_{3}{ }_{3}$ axis for the small element of volume dS $\Delta \mathrm{x}_{1}{ }_{1}$

Then taking into account that for a flexion of type 1 only stresses $\mathrm{T}^{\prime}{ }_{1}$ and $\mathrm{T}{ }_{6}$ are non-zero and using linear relations between stresses and strains the equation of motion is found to be

$$
\frac{4 d^{2}}{3 \rho s_{11}^{\prime}} u_{2,111}^{\prime}+\ddot{u}_{2}^{\prime}=0
$$

Where $\rho$ is the voluminal mass density, $\ddot{u}_{2}{ }_{2}$ the $x_{2}{ }_{2}$ component of the acceleration and s' ${ }_{11}$ is a primed compliance coefficient associated to the rotated system. The $x^{\prime}{ }_{1}$ and time $t$ dependent displacement $u_{2}{ }_{2}$ can be written as the product of two functions in which the influence of the two quantities is separated

$$
u_{2}^{\prime}\left(x_{1}^{\prime}, t\right)=g\left(x_{1}^{\prime}\right) f(t)
$$

Substituting Eq. 9 into the differential equation (8) and taking into account the boundary condition specific to a beam clamped at one end the resonance frequency is found to be

$$
\mathrm{f}_{\mathrm{F}}=\mathrm{X}_{\mathrm{n}}^{2} \frac{\mathrm{d}}{2 \pi \ell^{2}} \sqrt{\frac{1}{3 \rho \mathrm{s}_{11}^{\prime}}}
$$

where $\mathrm{X}_{\mathrm{n}}{ }^{2}$ depends on overtone number. For the first resonance frequency we have $\mathrm{X}_{\mathrm{n}}^{2}=3.516$.

Calculations for a flexion of type 2 can be treated by the same argument. The result follows readily since we have to interchange some physical quantities in Eqs. 8 to 10:

$$
\mathrm{x}_{2}^{\prime} \rightarrow \mathrm{x}_{3}^{\prime}, \ddot{\mathrm{u}}_{2}{ }_{2} \rightarrow \ddot{\mathrm{u}}_{3}^{\prime}, \mathrm{u}_{2}^{\prime} \rightarrow \mathrm{u}_{3}^{\prime}, \Delta \mathrm{M}_{\mathrm{x}_{3}^{\prime}} \rightarrow \Delta \mathrm{M}_{\mathrm{x}_{2}^{\prime}}, \mathrm{T}_{6}^{\prime} \rightarrow \mathrm{T}_{5}^{\prime}, \mathrm{d} \rightarrow \mathrm{w}
$$

\subsection{Torsional vibration modes}

Resonance frequency $\mathrm{f}_{\mathrm{T}}$ can be determined by adopting a theoretical framework based on the Saint-Venant hypothesis [30,31]. Hence for a beam with rectangular cross-section we proceed under the assumption that the state of strain is composed of

(i) A rotation of cross-sections similar to that occurring in the case of a cylindrical beam.

(ii) Warpings of cross-sections for which analogous formulas apply 
Hence the components of the displacement vector in the rotated system may be written as

$$
u_{1}^{\prime}=\delta_{o} \xi\left(x_{2}^{\prime}, x_{3}^{\prime}\right), \quad u_{2}^{\prime}=\delta_{o} x_{1}^{\prime} x_{3}^{\prime}, \quad u_{3}^{\prime}=\delta_{o} x_{1}^{\prime} x_{2}^{\prime}
$$

In Eq. $12 \delta_{0}$ is the angle of rotation by unit of beam length and $\xi\left(\mathrm{x}_{2}{ }_{2}, \mathrm{x}_{3}\right)$ is the SaintVenant function. Then we have to write the condition of mechanical equilibrium for the rectangular cross section

$$
\frac{\partial \mathrm{T}_{5}^{\prime}}{\partial \mathrm{x}_{2}^{\prime}}+\frac{\partial \mathrm{T}_{6}^{\prime}}{\partial \mathrm{x}_{3}^{\prime}}=0
$$

where stresses $\mathrm{T}_{5}{ }_{5}$ and $\mathrm{T}_{6}{ }_{6}$ are connected to non-zero strains $\mathrm{S}_{5}{ }_{5}$ and $\mathrm{S}_{6}{ }_{6}$ by linear relations in matrix form. Combining these stress-strain relations with Eq. 12, Eq. 13 becomes an equation of partial derivative with respect to the Saint-Venant function. This equation is solved with the condition of zero stresses on faces perpendicular to longitudinal axis $\mathrm{x}_{1}{ }_{1}$. As a result the Saint-Venant function can be expressed in terms of a series

$$
\xi\left(x_{2}^{\prime}, x_{3}^{\prime}\right)=x_{2}^{\prime} x_{3}^{\prime}-\frac{8 d^{2}}{\pi^{3}} \sqrt{\frac{C_{55}^{\prime}}{C_{66}^{\prime}}} \sum_{n=0}^{\infty} A_{n}
$$

With the coefficients of the expansion

$$
A_{n}=(-1)^{n}(2 n+1)^{-3} \sin \left(\frac{(2 n+1) \pi x_{2}^{\prime}}{d}\right) \frac{\sinh \left(\frac{(2 n+1) \pi x_{3}^{\prime}}{d} \sqrt{\frac{C_{66}^{\prime}}{C_{55}^{\prime}}}\right)}{\cosh \left(\frac{(2 n+1) \pi \mathrm{w}}{2 d} \sqrt{\frac{C_{66}^{\prime}}{C_{55}^{\prime}}}\right)}
$$

Then we write the moment $\mathrm{M}_{\mathrm{t}}$ due to shears tangential to the cross section CS

$$
M_{t}=\iint_{C S}\left(x_{2}^{\prime} T_{5}^{\prime}-x_{3}^{\prime} T_{6}^{\prime}\right) d x_{2}^{\prime} d x_{3}^{\prime}
$$

This moment is found to be proportional to the rotation angle according to

$$
\mathrm{M}_{\mathrm{t}}=\delta_{\mathrm{o}} \mathrm{C}_{\mathrm{t}}
$$

where $C_{t}$ is the coefficient of torsion. Calculations yield

$$
C_{t}=\frac{C_{55}^{\prime} w^{3}}{3}\left(1-\frac{192}{w} d \sqrt{\frac{C_{55}^{\prime}}{C_{66}^{\prime}}} \sum_{n=0}^{\infty} \frac{1}{(2 n+1)^{5} \pi^{5}} \tanh B\right), \quad B=\frac{(2 n+1) \pi w}{2 d} \sqrt{\frac{C_{66}^{\prime}}{C_{55}^{\prime}}}
$$

Equation 18 shows that the coefficient of torsion depends on the dimensions of the rectangular cross section and on primed elastic stiffness $C^{\prime}{ }_{55}$ and $C^{\prime}{ }_{66}$. Series involved in Eqs. 14 and 18 are strongly convergent. Hence we limit the expansion to fourth-order term to 
compute $\mathrm{C}_{\mathrm{t}}$. The dynamics response of a resonator vibrating on torsion modes is governed by a differential equation involving the torsion angle $\alpha\left(\mathrm{x}^{\prime}{ }_{1}, \mathrm{t}\right)$ and the moment of inertia I

$$
\rho \mathrm{I} \frac{\partial^{2} \alpha}{\partial \mathrm{t}^{2}}-\mathrm{C}_{\mathrm{t}} \frac{\partial^{2} \alpha}{\partial \mathrm{x}_{1}^{\prime 2}}=0
$$

The harmonic solution of the above differential equation is found taking into account boundary conditions for a cantilever

$$
\alpha\left(\mathrm{x}_{1}^{\prime}, \mathrm{t}\right) \prec \sin \left(\mathrm{n} \pi \mathrm{x}_{1}^{\prime} / \ell\right) \cos \omega \mathrm{t}
$$

Finally writing the energy conservation's principle yield the resonance frequency $f_{T}$ as

$$
\mathrm{f}_{\mathrm{T}}=\ell^{-1} \sqrt{3 \mathrm{C}_{\mathrm{t}}\left[4 \rho\left(\mathrm{w}^{3} \mathrm{~d}+\mathrm{wd}^{3}\right)\right]^{-1}}
$$

\subsection{Discussion}

Theoretical values of resonance frequencies $f_{\mathrm{F}}$ and $\mathrm{f}_{\mathrm{T}}$ are determined from Eqs. 10 and 21 for a standard cantilever with vertical walls. Dimensions of the cantilever are $\ell=420 \mu \mathrm{m}, \mathrm{w}=$ $70 \mu \mathrm{m}$ and $\mathrm{d}=25 \mu \mathrm{m}$. In Table 4 we list the results for the selected $X$ cut and cantilever alignments identified in Tables 2 and 3. For the $X$ cut vibrating in flexion mode we observe that the frequency $\mathrm{f}_{\mathrm{F}}$ is about three times lower for the flexion type $1\left(\mathrm{f}_{\mathrm{F}}\right.$ close to $\left..1 \mathrm{MHz}\right)$ than for the flexion type 2. In the case of excitation of $\mathrm{X}$ and $\mathrm{Y}$ cuts in a torsion mode the frequency $\mathrm{f}_{\mathrm{T}}$ is close to $1 \mathrm{MHz}$.

In practice the metrological performance of LGS resonant cantilevers may be altered by fabrication process. The most common sources of deviations from theoretical predictions are:

(i) Deviations from expected cantilever dimensions $\ell$, $d$ and $w$ caused by a micromachining prolonged after the opening of the resonant structure.

(ii) Misalignment of the mask that produces a deviation $\Delta \psi$ with respect to optimal alignment $\psi$.

To study the influence of cantilever dimensions on the resonance frequency we have to consider separately the different modes of vibration. Firstly we turn attention on the $\mathrm{X}$ cut and on the flexion modes excited by the two electrode configurations A and B. Figure 6 shows for the flexion of type 1 relative changes in resonance frequency $\Delta \mathrm{f}_{\mathrm{F}} / \mathrm{f}_{\mathrm{F}}$ as a function of relative changes in length $\ell$ and in thickness $d$. Note that as we are concerned with relative changes of influencing parameters plot of $\Delta \mathrm{f}_{\mathrm{F}} / \mathrm{f}_{\mathrm{F}}$ as a function of $\Delta \mathrm{w} / \mathrm{w}$ for the flexion type 2 will be similar to plot of $\Delta \mathrm{f}_{\mathrm{F}} / \mathrm{f}_{\mathrm{F}}$ as a function of $\Delta \mathrm{d} / \mathrm{d}$ as drawn in Fig. 6 . It can be seen that the plot of $\Delta \mathrm{f}_{\mathrm{F}} / \mathrm{f}_{\mathrm{F}}$ as a function of $\Delta \mathrm{d} / \mathrm{d}$ is linear with a slope equal to 1 in accord with the theoretical prediction of Eq. 10. A converse behavior is observed for $\Delta \mathrm{f}_{\mathrm{F}} / \mathrm{f}_{\mathrm{F}}$ against $\Delta \ell / \ell$. The behavior is characterized by non linear variations and by a decrease of the resonance frequency with increasing length. At this point let us outline that a relative change of $10 \%$ in width and thickness correspond to deviation of $7 \mu \mathrm{m}$ and $2.5 \mu \mathrm{m}$ with respect to the standard cantilever. For the LGS crystal that undergoes an anisotropic etching of type 2 [19] it is clear that for some orientations and cantilever alignments the underetch beneath the mask can cause such change in width. Moreover deviating behavior of experimental parameters (etching duration, 
temperature of etching bath) can result in relative changes of $\pm 10 \%$ both in width $\mathrm{w}$ and in thickness $d$ yielding equivalent relative changes in frequency. Influence of length cannot be neglected because a small error of 5\% in final length induces an error of $-10 \%$ in resonance frequency. Moreover owing to the converse behaviors of the two plots of Fig. 6 it is essential to undertake a complete study of the final 3D etching shape.

Typical behaviors for a standard Y cantilever vibrating in torsion mode are plotted in Fig. 7. The two plots of $\Delta \mathrm{f}_{\mathrm{T}} / \mathrm{f}_{\mathrm{T}}$ as a function of $\Delta \mathrm{d} / \mathrm{d}$ and as a function of $\Delta \ell / \ell$ are now non linear. Here again the resonance frequency decreases (increases) with length (thickness). However we observe less marked changes of the frequency in the case of torsion than in the case of flexion especially for changes caused by variations in length.

It is also interesting to follow changes in the resonance frequency induced by misalignment of the cantilever. Numerical calculations are performed to plot $\mathrm{f}_{\mathrm{F}}$ and $\mathrm{f}_{\mathrm{T}}$ against $\Delta \psi$ for flexion (type 1) and torsion modes respectively (Fig. 8). We observe:

i) Non linear variations of frequencies $\mathrm{f}_{\mathrm{F}}$ and $\mathrm{f}_{\mathrm{T}}$ with increasing misalignment $\Delta \psi$.

ii) Negligible changes in resonance frequency for cantilevers vibrating on a torsion mode. $\left(\Delta \mathrm{f}_{\mathrm{T}} \leq .7 \%\right.$ for $\left.\Delta \psi<5^{\circ}\right)$

iii) More marked changes for the flexion mode with deviation reaching $4 \%$ when $\Delta \psi=5^{\circ}$.

\section{MICROMACHINING AND SIMULATIONS}

\subsection{The simulator TENSOSIM}

Before attempting to comment the software of the simulation tool TENSOSIM let us look briefly to the theoretical framework of the numerical simulation. For this purpose let be consider a mask opened on a wafer plane and an oriented surface element $\mathbf{d S}$ of orientation $(\varphi, \theta)$ potentially present at the mask edge. We have to track the displacement of $\mathbf{d S}$ within the crystal during the chemical attack. The way to solve this problem is to adopt a model derived from kinematic wave theory $[32,33]$. This 3D model (KT model) that combines kinematic theory and tensorial formulation constitutes an extension to the $2 \mathrm{D}$ model previously proposed by Frank [32]. There are three points of great importance on which the KT model is constructed

(1) For chemical etchings governed by orientation alone, a surface element $\mathbf{d S}$ moves along a linear trajectory into the wafer. Consequently we may assign a displacement vector $\mathbf{P}$ of components $\mathrm{dx}_{1}, \mathrm{dx}_{2}$ and $\mathrm{dx}_{3}$ to $\mathbf{d S}$.

(2) Theoretical expressions for the components of $\mathbf{P}$ may be derived from the analytical equation for the dissolution slowness surface proposed by C. Tellier [34, 35]. This dissolution slowness surface is just the representative surface of a dissolution slowness vector $\mathbf{L}$ associated to a moving surface element $\mathbf{d S}$ whose magnitude $\|\mathbf{L}\|=\mathrm{f}(\varphi, \theta)$ is the reciprocal of the etch rate and whose positive direction is that of the unit inward normal $\mathbf{n}$ to $\mathbf{d S}$. So under the assumption that the dissolution slowness is only orientation dependent the KT model allows us to compute the displacement $\mathbf{P}$ of all surface elements potentially present at mask edges. 
(3) A simple method to construct the analytical equation $f(\varphi, \theta)$ for the representative surface is to use a tensorial formulation:

$$
\mathrm{f}(\varphi, \theta)=\mathrm{L}\left(\mathrm{n}_{1}, \mathrm{n}_{2}, \mathrm{n}_{3}\right)=\mathrm{D}_{0}+\mathrm{D}_{\mathrm{i}} \mathrm{n}_{\mathrm{i}}+\mathrm{D}_{\mathrm{ij}} \mathrm{n}_{\mathrm{i}} \mathrm{n}_{\mathrm{j}}+\mathrm{D}_{\mathrm{ijk}} \mathrm{n}_{\mathrm{i}} \mathrm{n}_{\mathrm{j}} \mathrm{n}_{\mathrm{k}}+\ldots
$$

Where $\mathrm{D}_{\mathrm{i}}, \mathrm{D}_{\mathrm{ij}}, \mathrm{D}_{\mathrm{ijk}}, \ldots$ are components of dissolution tensors of rank $0,1,2, \ldots$ It is expected that observation data including etching shapes and etch rate data will provide values of dissolution constants. The number of dissolution constants is reduced by:

(1) Arguing that permutations of inward normal components in Eq. 22 give identical dissolution constants (i.e. applying this rule we have $\mathrm{D}_{123}=\mathrm{D}_{132}=\mathrm{D}_{213}=\mathrm{D}_{231}=\mathrm{D}_{312}=\mathrm{D}_{321}$ )

(2) Accounting for the symmetry of the crystal.

For the langasite crystal that belongs to class 32 only two elements of symmetry may be considered: the two-fold $\mathrm{x}_{1}$ axis and the three-fold $\mathrm{x}_{3}$ axis. Simple but cumbersome calculations allow us to establish relations (Table 5) between non-zero dissolution constants. Taking further into account condition (1) we finally expand Eq. (22) to obtain an analytical expression $\mathrm{L}(\varphi, \theta)$ that at each tensor rank R involved $v_{\mathrm{R}}$ independent constants (Table 5).

At this point it must be recall that to create a representative surface with peaky protuberances and narrow valleys it is necessary to work with tensors of high rank. In the present case the database is composed of dissolution constants related to tensors of rank 7 to 10 that were determined from experiments.

The software of the self elaborated simulator TENSOSIM $[38,39]$ consists of six principal steps according to the flow chart of Fig. 9. Let be a mask of more and less complicated shape whose contour presents successive convex or concave intersections $I_{n}$ (Fig. 10) be patterned on a reference surface with orientation $\left(\varphi_{0}, \theta_{0}\right)$. In practice we have to work with all crosssections $S_{k}$ present at an intersection $I_{n}$. A section $S_{k}$ is now defined by three angles $\varphi, \theta$ and $\psi$. In step 1.3D we work with successive sections $S_{k}$ and in a section $S_{k}$ the dissolution profile is composed of successive elements $\mathrm{E}_{\mathrm{ki}}$ (Fig. 10a). For convention the horizontal element $\mathrm{E}_{\mathrm{N}}$ related to the wafer plane is located as $\alpha_{N}=0^{\circ}$ consequently angle $\alpha_{i}$ varies from $-180^{\circ}$ to $0^{\circ}$. Step 3.3D merits also comments. In a cross-section $S_{\mathrm{k}}$ extremities of displacements $\mathbf{P}_{\text {Eki }}$ create an oriented path showing crossings (Fig. 11a). To extract the final dissolution profile beneath the mask (in bold line in Fig. 11a) we have to eliminate such crossings. For this purpose special algorithms called "eliminating tests" are elaborated. As a result of step 3.3D final dissolution profiles are determined in successive cross sections $S_{k}$. A dissolution profile intersects a plane parallel to the reference surface at point $\mathrm{D}_{\mathrm{hi}}$. Step $4.3 \mathrm{D}$ shows that points $\mathrm{D}_{\mathrm{hi}}$ related to successive dissolution profiles generate a path in the horizontal plane into consideration with here again some crossings. In step 5.3D these crossings disappear by means of specific eliminating tests. This procedure gives finally a $3 \mathrm{D}$ etching shape as a constant level representation.

\subsection{Simulations}

An anisotropy of type 2 was recently observed [21] for the chemical attack of LGS plates in $\mathrm{HCl}: \mathrm{H}_{2} \mathrm{O}$ of composition 2:1. The satisfactory database (dissolution constants of ranks 7 to 10) extracted from experimental data is introduced in the simulator TENSOSIM to derived theoretical shapes for 3D cantilevers. Let us start with a LGS wafer $150 \mu \mathrm{m}$ thick with double sided masks. A two step procedure is performed to obtain a cantilever $25 \mu \mathrm{m}$ thick at the 
opening of the structure. A rectangular membrane (125 $\mu \mathrm{m}$ thick) is firstly micromachined on the lower surface of the wafer. Further etching of the upper surface causes the opening of the cantilever. Figures 12 to 15 show theoretical shapes of resonant structures etched on selected cuts. Shapes are derived for an etching duration that ensures the structure opening. Drawings of top shapes of cantilevers can be found in (a). Cantilevers built-ins (cross sections AA') and cross-sections CC' are viewed in (b) and (c) respectively. From a technical point of view or from a mechanical point of view the following three situations are considered to be favorable:

(1) Nearly vertical lateral edges for cantilevers excited with the electrodes configuration B.

(2) No re-entrant profiles for cross-sections AA' (see Fig. 15 b for example).

(3) Nearly similar slopes for the two lateral edges (as in figs. 12a2, 14a and 15a).

(4) Symmetrical built-ins. A perfect symmetry may be observed for example in the case of the theoretical cantilever displayed in Figs. 12a2.

Point (1) constitutes a severe technical requirement. Looking at Fig. 12a it appears that simulations predict the formation of two markedly different cantilever edges namely a vertical edge and an inclined edge (inclination angle with a mean value close to $40^{\circ}$ ). Consequently the orientation ( $\mathrm{Y}$ cut, $\Psi=90^{\circ}$ ) selected in above section to fabricate a cantilever vibrating in torsion must be rejected even if built-in exhibits (Fig. 12b1) a suitable cross sectional shape.

Points (2) and (4) are expected to be explored by an analysis based on a Finite Elements Method. Such an analysis may be of interest for a cantilever micromachined on a Y cut and aligned at $225^{\circ}$. Simulations (Fig. 13) reveal that etching causes the formation of an adequate cross-section together with nearly symmetrical built-ins on both sides of the beam. However the cantilever section $\mathrm{CC}^{\prime}$ in Fig. 13c is composed of edges with different features (an inclined edge with outward normal and a re-entrant edge). At this point it is important to remark that:

(i) Previous study [40] has shown that the shape of cantilever cross section does not decrease dramatically metrological performances of resonant beams.

(ii) An electrode configuration of type $\mathrm{A}$ is used to excite piezoelectrically this Y-cut cantilever and consequently the influence of shape (Fig.13c) is not so critical.

(iii) The two faces of a Y cut are etched with the same dissolution slowness making the dimensioning of masks on the two faces more easy.

In contrast with the $\mathrm{Y}$ cut the two faces of an $\mathrm{X}$ cut have different dissolution slowness (Lface1/Lface $2 \cong 3.2$ ) so the fabrication is complicated: the identification of the $X$ face is now necessary and adjustment of dimensions for the doubled sided masks is required. Figures 14 and 15 refer to cantilevers vibrating in flexion (alignment $\psi=180^{\circ}$ for the two faces). Theoretical simulations as derived by the simulator TENSOSIM call for several remarks:

(i) The micromachining of the resonant beam on face 1 results in a beam with nearly vertical lateral edges (Fig. 14c), with a crudely perfect vertical built-in (Fig. 14a) and with a smoothly inclined shoulder (Fig. 14 b). Such a resonant beam can be considered as adequate for the two types of flexion.

(ii) If the micromachining is performed on face 2 the symmetrical beam edges are composed of two facets, one facet is somewhat vertical and the terminal facet is inclined at 
about $40^{\circ}$. The vacuum deposition of lateral electrodes on such edges does not constitute a good solution for the piezoelectric excitation. However here again the built is perfectly symmetric making interesting the face 2 for a flexion in the $\left(\mathrm{x}_{1}{ }_{1}, \mathrm{x}^{\prime}{ }_{3}\right)$ plane (flexion of type 2$)$.

Hence owing to these two remarks the orientation (Y cut) and the alignment $\psi=225^{\circ}$ are retained for microfabrication tests. In the case of the $Y$ cut and of cantilever vibrating in torsion mode this alignment is the alone alignment possible. Effectively for the other alignments determined in Table 3 the micromachining is found to create highly asymmetric built-ins.

In practice only the $\mathrm{X}$ cut appears to be very interesting for the design of new LGS microresonators. So Table 6 furnishes information on the final selection and on corresponding theoretical resonance frequency (Theory, case2). For all selected alignments final dimensions of cantilever calculated by the simulator are introduced in computation of the resonance frequency.

\section{FEM ANALYSIS}

A Finite Element Method (FEM) is used to compute vibrations for various cantilevers listed in Table 4. In a first step FEM simulations are performed for cantilevers having on the one hand the geometry characterized by vertical walls and on the other hand average values for length and width as evaluated from simulations. The FEM analysis takes into account the anisotropy of LGS crystal and calculates the elastic coefficients for all selected orientations. Table 6 gives values as computed from analytical models (Theory, case 2) and as evaluated by the simulator COMSOL ${ }^{\circledR}$. Stress mappings related to $\mathrm{X}$ cantilevers are displayed in Fig. 16.

Let us firstly compare theoretical values of the resonance frequency as computed in cases 1 (Table 4) and 2 (Table 6). As the two faces of an X cut dissolve with different etch rates the simulator gives mean values of $\ell$ and $\mathrm{w}$ that show relatively marked differences (about $40 \%$ for $\ell$, see Figs. 14b and 15b). Consequently the resonant frequency of an $\mathrm{X}$ cut vibrating in flexion depends strongly on the face on which the mask is patterned. Moreover for all selected orientations simulations furnish length and width that deviate from standard $\ell$ and $\mathrm{w}$. In fact deviation reaches more than $30 \%$ in most cases showing that firstly dimensions of the mask pattern must be subjected to important corrections and that secondly the etching parameters (duration of etching, temperature) must be carefully supervised during the micromachining process. Secondly the comparison (Table 6) of theoretical results with FEM results as obtained in case 2 is quite successful. Values of the resonance frequency as collected in the third column of Table 6 are close to theoretical values. There is a maximum discrepancy of $2 \%$ and $4 \%$ between theoretical and FEM values for flexions type 1 and 2 respectively.

Owing to this satisfactory agreement tentative are then made to apply the FEM analysis to final shapes of cantilevers as derived by the simulator TENSOSIM. It is reasonable to assume that the shape of cantilever built-in has also an influence on the resonance frequency. In particular different behaviors are expected for two cantilevers having

i) For one cantilever a smooth built-in composed of successive profile elements with outward normal. Figure $14 \mathrm{~b}$ gives a good example of smooth built-in.

ii) For the other cantilever a sharp built-in characterized by a re-entrant profile (see Fig. 15b) 
So the main objective is now to study the influence of the final etching shape of the crosssection AA' on the performance of resonant cantilevers. Hence in a second step the 3D shapes furnished by the simulator are introduced in the simulator COMSOL $\AA$ for the meshing. As section 4.2 reveals that the longitudinal cross-sectional shapes of $\mathrm{X}$ cantilevers aligned along the $\mathrm{Y}$ axis $\left(\psi=180^{\circ}\right)$ can illustrate conveniently the two expected different behaviors the FEM analysis now focuses on $\mathrm{X}$ cantilevers vibrating in flexion. Active stress components are plotted across the cantilever area for the cross sectional shapes drawn in Figs. 14b and 15b for the two types of flexion (Figs.16 and 17). Clearly in the case of the flexion of type 1 we can in the region of maximum stress depict differences between stress mappings as viewed in Figs. $16 \mathrm{a}$ and $16 \mathrm{~b}$. In addition shifts $\Delta \mathrm{f}_{\mathrm{F}}$ of the resonance frequency are numerically evaluated (Table 7). As expected changes in resonance frequency result from modification in the standard rectangular shape. Moderate falls are observed for the cantilever etched on face 1 characterized by a smooth longitudinal profile. In contrast a re-entrant profile as that formed in the case of the cantilever micromachined on face 2 induces for the two flexion modes marked increases in the resonance frequency with deviations reaching $50 \%$. Consequently the face 2 seems to be less favourable than the face 1 for flexural modes.

\section{CONCLUSION}

An analytical model for the piezoelectric excitation of langasite cantilevers is proposed. Theoretical expressions of the resonance frequency are derived for cantilevers defected by pure flexion modes or submitted to a pure torsion. The possibility with commercial cuts to design cantilevers vibrating in two pure flexion modes or in pure torsion mode is explored. For the selected cuts and cantilever alignments the resonance frequency is evaluated. To our knowledge the proposed selection is new. Effectively the recent work of Ansorge et al is concerned with a $\mathrm{Y}$ cut and a cantilever aligned along the $\mathrm{X}$ axis $\left(\psi=0^{\circ}\right)$ that is defected by a shear strain. So in contrast with the present work the Y cantilever of Ansorge does not vibrate on a pure mode. The wet etching is the process retained for the microfabrication of the cantilever. The wet etching of the LGS crystal that was recently found to be characterized by an anisotropy of type 2 is conveniently described by a 3D tensorial and kinematic model whose theoretical basis are given. In particular relations between the independent dissolution constants are listed in order to make possible the tensorial formulation of the dissolution slowness surface. The principal steps of the self elaborated simulator TENSOSIM that starts with this analytical formulation are described and emphasis is placed on how we find a way: 
i) To decompose in successive surface elements the starting surface that is demarcated by a complex mask contour composed of concave and convex regions.

ii) To perform eliminating tests.

Theoretical 3D etching shapes are then derived for the previously retained cantilevers. The final selection of cantilevers takes into account the "symmetry" of the cantilever with respect to the longitudinal axis and the formation of nearly vertical lateral edges. With the symmetry requirement only the $\mathrm{X}$ cut is retained for the pure torsion mode. In addition the influence on resonance frequency of the longitudinal built-in shape is studied by a FEM analysis. As a main result a re-entrant built-in causes a vibrating behavior that differs markedly from that observed for a smooth built-in. Owing to the marked frequency shift produced by a re-entrant built-in the final selection for flexion mode falls on a cantilever micromachined on face 1 of the $X$ cut. The $X$ cut is found to be the best cut for LGS resonant cantilevers vibrating in flexural modes (type 1 and type 2) or in torsion mode. Whatever is the vibration mode the cantilever must be etched on the face 1 of the X cut. Care must be taken that the resonance frequency depends on final length and width or thickness. Hence the simulation is also a help to the dimensioning of masks patterned on the two faces of the selected cut.

Finally the CAD design that combines computations of metrological performances, simulation of micromachined shapes and FEM analysis confirms that it is possible to fabricate resonant cantilevers vibrating in flexural modes (type 1 and type 2) or in torsion mode with the commercial X cut. The micro-fabrication of X cantilevers as well as tests on metrological performances will be investigated in the future. 


\section{References}

1. W.G. Cady, Piezoelectricity, Vol 1, Dover, New York, NY, 1946

2. E.P. Eernisse, R.W. Ward, R.B. Wiggins, IEEE Trans. Ultrason. Ferroelectr. Freq. Control, 35 (1988) 323-330

3. D.S. Ballantine, R.M. White, S.J. Martin, A.J. Ricco, E.T. Zellers, G.C. Frye, H. Wohltjen, Acoustic Wave Sensors, Academic Press, San Diego, CA, 1997

4. J. Zhang, C.C. Dai, X.D. Su, S.J. O’Shea, Sens. Actuators B, 84 (2002) 123-128

5. V.M. Mecea, Sens. Actuators A, 40 (1994) 1-27

6. M. Dufour, M.T. Delaye, F. Michel, J.S. Danel, B. Diem and G. Delapierre, Sens. Actuators A, 34 (1992) 201-209

7. J.S. Danel, F. Michel and G. Delapierre, Sens. Actuators A, 23 (1990) 971-977

8. J. Liang, F. Kohsaka, T. Matsuo and T. Ueda, IEEJ Trans. Sens. Micromachines, 127 (2007) 337-342

9. C.R. Tellier, T.G. Leblois, IEEE Trans. Ultrason. Ferroelectr. Freq. Control, 47 (2000) 1204-1216

10. T. Leblois, Advances in Science and Technology 51 (2006), 191-196

11. H. Fritze, H. Tuller, H. She and G. Borchardt, Sens. Actuators B, 76 (2001) 103-107

12. H. She, H.L. Tuller, H. Fritze, Sens. Actuators B, 93 (2003) 169-174

13. E. Ansorge, S. Schimpf, S. Hirsch, J. Sauerwald, H. Fritze and B. Schmidt, Sens. Actuators A, 130-131 (2006) 393-396

14. E. Ansorge, S. Schimpf, S. Hirsch, J. Sauerwald, H. Fritze and B. Schmidt, Sens. Actuators A, 132 (2006) 271-277

15. S. Laffey, M. Hendricson, J.R. Vig, in Proceedings of the IEEE Int. Frequency Control Symposium 1994, (IEEE, 1994, pp 245-250)

16. H. Hyoung, K.B. Shim, K.H. Auh, T. Fukuda, Materials Letters, 46 (2000) 354

17. H. Takeda, S. Okamura, T. Shiosaki, J. Mater. Sci., 21 (2002) 1117

18. C.R. Tellier, Research Report $\mathrm{N}^{\circ}$ 03034020, DGA, Paris, (2006)

19. C.R. Tellier, M. Akil, T.G. Leblois, in Proceedings of the 2006 IEEE Ultrasonic Symposium, Vancouver, Canada, 2006, p.1931-1934

20. C.R. Tellier, M. Akil, T.G. Leblois, in Proceedings of the IEEE International Frequency Control Symposium, Geneva, Switzerland, 2007, p. 671-677

21. C.R. Tellier, M. Akil, T.G. Leblois, in Proceedings of $22^{\text {th }}$ European Frequency Control symposium, Toulouse, France, 2008, 9pp

22. T.R. Meeker, IEEE Standard on Piezoelectricity, ANSI/IEEE Std 176-1987

23. B. Mill and Y. Pisarevsky, in Proceedings of IEEE International Frequency Control Symposium, Kansas City, MO June 2000, p. 133-144

24. D. Malocha, M. Pereira da Cunha, in Proceedings of IEEE International Frequency Control Symposium, Seattle, Wa., 2001, p. 291-295

25. M. da Cunha and D. Malocha, IEEE Trans. on Ultrason. Ferroelectr. Freq. Control, 49 (2002) 656-662

26. S. Smythe, E. Hague, in Proceedings of the IEEE International Frequency Control Symposium, Kansas City, MO, 2000, p. 191-194

27. D. Malocha, H. François-Saint-Cyr, K. Richardson, R. Helmbold, IEEE Trans. Ultrason. Ferroelectr. Freq. Control, 49 (2002) 350-355

28. J. Kosinski, R. Pastore, M. Pereira da Cunha, D. Malocha, J. Detaint, E. Bigler, in Proceedings of IEEE International Frequency Control Symposium, Seattle, Wa., 2001, p. 278-286

29. T.G. Leblois, C.R. Tellier, in Proceedings of the 2006 IEEE Ultrasonic Symposium, Vancouver, Canada, 2006, p. 1918-1921 
30. A. Love, A treatise on the mathematical theory of piezoelectricity, Dover, New York, NY, 1944, pp 381-443

31. C.R. Tellier, T.G. Leblois, Sens. Actuators A, 132 (2006) 224-235

32. F.C. Frank in Growth and Perfection of Crystals edited by R.H. Doremus, B.W. Robert and D. Turnbull, Wiley, New York, 1965, p 411

33. K. Sangwal, Etching of Crystals, North Holland, Amsterdam, 1987

34. C.R. Tellier, N. Vialle, J.L. Vaterkowski, Surface Coatings Technol., 34 (1988) 417

35. C.R. Tellier and J.L. Vaterkowski, J. Mater. Sci., 24 (1989) 1077-1088

36. W. Don Shaw, J. Electrochem. Soc/ Solid State Sci. Technol., 128 (1981) 874-880

37. C.R. Tellier, J.Y. Amaudrut, A. Brahim-Bounab, J. Mater. Sci., 26 (1991) 5595-5607

38. C.R. Tellier, J. Mater. Sci., 33 (1998) 117-131

39. C.R. Tellier, A. Charbonnieras, Sens. Actuators A, 105 (2003) 62-65

40. C.R. Tellier, T.G. Leblois, S. Durand, In Proceedings of the $18^{\text {th }}$ workshop on

Micromachining, Micromechanics and Microsystems, Guimareas, Portugal, 2007, pp 19-22 


\section{Captions to Figures}

Figure 1: Definition of primed axes. (a) Wafer orientation and (b) cantilever alignment.

Figure 2: Electrodes configurations and associated electric field lines. (a), (b) and (c,d) are for configuration $\mathrm{A}$ and configuration $\mathrm{B}$ respectively.

Figure 3: Electronic field lines associated with pure flexion modes. (a) and (b) are for flexion type 1 and flexion type 2 respectively.

Figure 4: Polar plots of primed coefficients $d^{\prime}{ }_{21}$ and $d^{\prime}{ }_{31}\left(\times 10^{-12} \mathrm{~V} / \mathrm{m}\right)$. Plots (a) and (b) are for the Y cut. Plot (c) is for the X cut.

Figure 5: Polar plots of "shear coefficients". Graphs (a,b) and (c,d) are for the Y cut and the $\mathrm{X}$ cut respectively.

Figure 6: Relative changes in the resonant frequency $f_{F}$ with relative changes in thickness $d$ (1) and in length $\ell$ (2) for an X cantilever vibrating in flexion mode type 1.

Figure 7: Relative changes in the resonant frequency $\mathrm{f}_{\mathrm{T}}$ with relative changes in thickness $\mathrm{d}$ (1) and in length $\ell$ (2) for a Y cantilever vibrating in torsion.

Figure 8: Relative changes in the resonant frequencies as a function of misalignment $\Delta \psi$.

Curve (1) is for $\frac{\Delta f_{T}}{f_{T}}$ in the case of torsional mode. Curve (2) is for $\frac{\Delta f_{f}}{f_{f}}$ and for a flexion of type 1 .

Figure 9: The flow chart of the self-elaborated simulator TENSOSIM.

Figure 10: Geometry involved in step 1.3D. Identification of section in (a) and definition of angle $\alpha_{i}$ in (b)

Figure 11: Crossing trajectories in section $S_{k}($ a) and geometry involved in step 4.3D (b).

Figure 12: Simulations: (a1,b1) for cantilever etched on a $Y$ cut $\left(\psi=180^{\circ}\right)$ and $(\mathbf{a 2}, \mathbf{b 2})$ on the face 1 of an $\mathrm{X}$ cut $\left(\psi=90^{\circ}\right)$.

Figure 13: Simulations for a cantilever etched on a Y cut with alignment $\psi=225^{\circ}$.

Figure 14: Simulations for the face 1 of an $X$ cut and an alignment along $Y$ axis $\left(\Psi=180^{\circ}\right)$.

Figure 15: Simulations for the face 2 of an $X$ cut and an alignment along $Y$ axis $\left(\Psi=180^{\circ}\right)$.

Figure 16: Stress mappings as derived for cantilevers with mean dimensions as evaluated from simulations. Mappings (a), (b) and (c) are for the X cut and for flexion type 1, flexion type 2 and torsion modes respectively. Regions with maximum and minimum stresses are identified on graphs. 
Figure 17: Stress mappings as derived for simulated $X$ cantilevers. Mappings (a) and (b) are for the flexion type 1 and for faces 1 and 2 respectively. For convenience regions with maximum and minimum stresses are identified on graphs.

Figure 18: Stress mappings as derived for simulated $X$ cantilevers. Mappings (a) and (b) are for the flexion type 2 and for faces 1 and 2 respectively. For convenience regions with maximum and minimum stresses are identified on graphs. 


\section{Table Captions:}

Table 1: Reference values $\left(\varphi_{0}, \theta_{0}\right)$ for the angles of cuts of "commercial" $y$ - and x-cuts.

Table 2: Selection for the $\mathrm{X}$ cut: Alignment $\psi$, electrode configuration, type of flexion Corresponding primed coefficient $\mathrm{d}_{21}$ (in $\mathrm{V} / \mathrm{m}$ ).

Table 3: Selected cuts, electrode configuration and corresponding primed shear coefficients (in $\mathrm{V} / \mathrm{m}$ ). $\mathrm{n}$ is a positive integer.

Table 4: Values of the resonance frequencies (in $\mathrm{MHz}$ ) as computed from Eqs. 10 and 21 (Theory, case 1). Case 1 corresponds to the standard cantilever defined in section 3.3.

Table 5: Relations between non-zero constants and number $v_{R}$ of independent constants. In this table we adopt the notation $\mathrm{D}_{1\left(\mathrm{~N}_{1}\right) 2\left(\mathrm{~N}_{2}\right) 3\left(\mathrm{~N}_{3}\right)}$ where $\mathrm{N}_{1}, \mathrm{~N}_{2}$ and $\mathrm{N}_{3}$ are the number of subscripts 1, 2 and 3 respectively. Note that $\mathrm{N}_{1}+\mathrm{N}_{2}+\mathrm{N}_{3}$ is equal to the tensor rank $\mathrm{R}$.

Table 6: Values of the resonance frequencies (in $\mathrm{MHz}$ ) as computed from Eqs. 10 and 21 (Theoretical, case 2) and as evaluated from FEM analysis. Case 2 is for an X cantilever with vertical walls but with mean length and width as derived from simulations of etching shapes.

Table 7: Frequency shifts for the two types of flexion. 


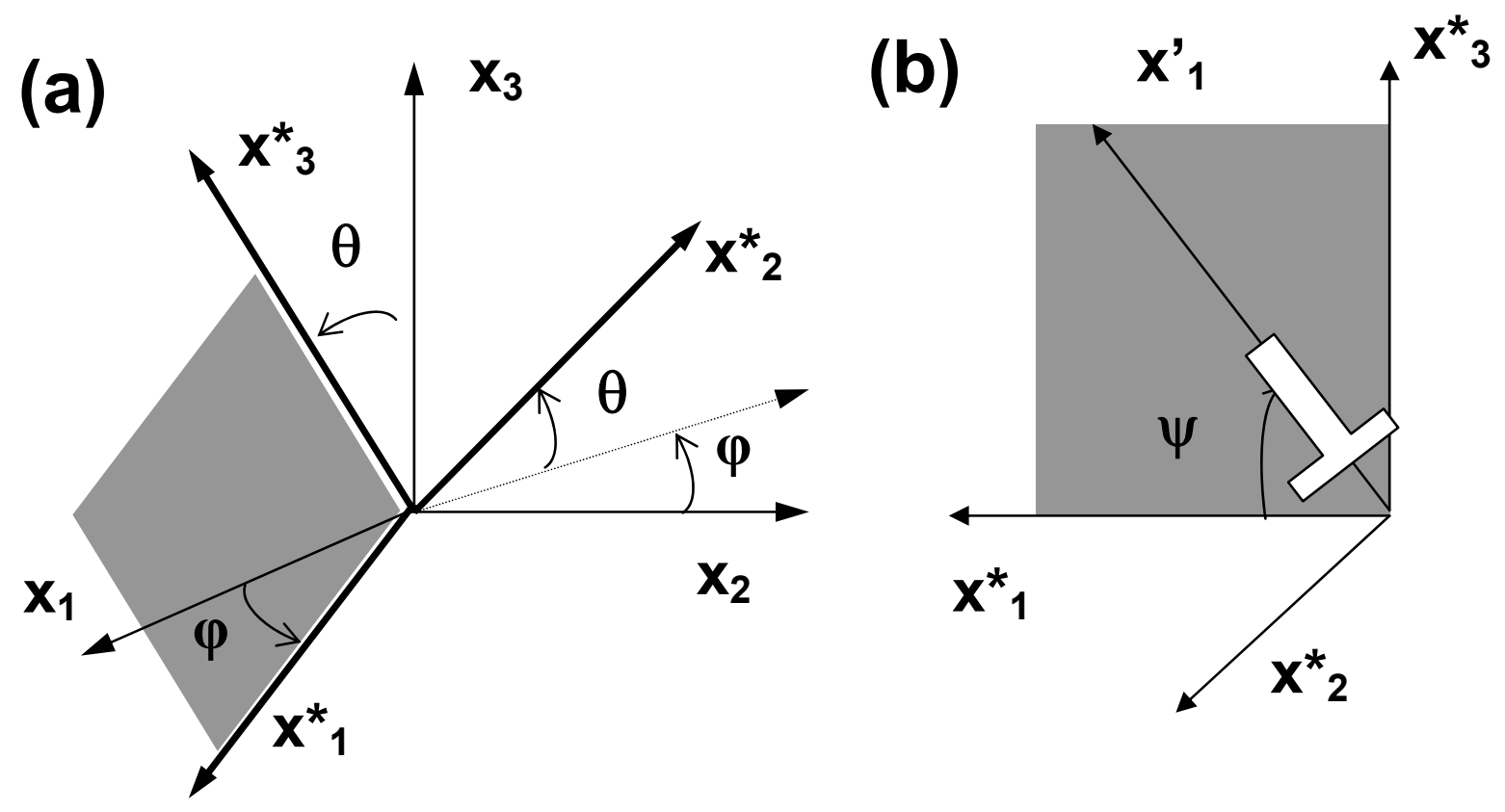

Figure 1: Definition of primed axes. (a) Wafer orientation and (b) cantilever alignment 


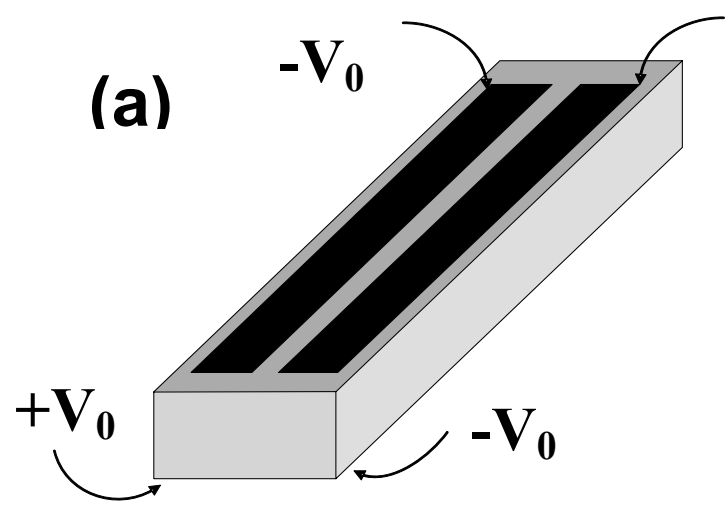

$+V_{0} \quad$ (b)
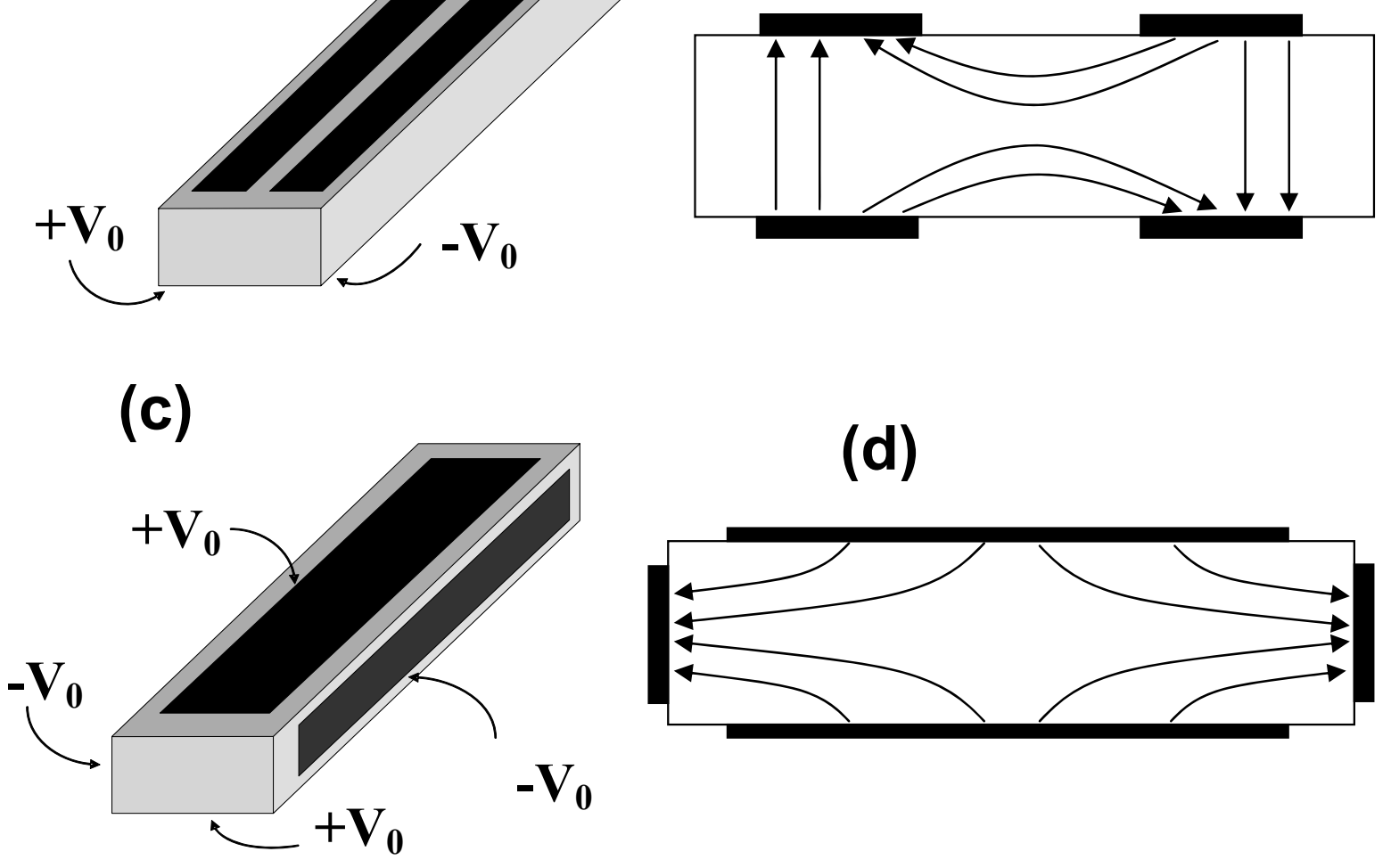

Figure 2: Electrodes configurations and associated electric field lines. (a), (b) and (c,d) are for configuration $\mathrm{A}$ and configuration $\mathrm{B}$ respectively 

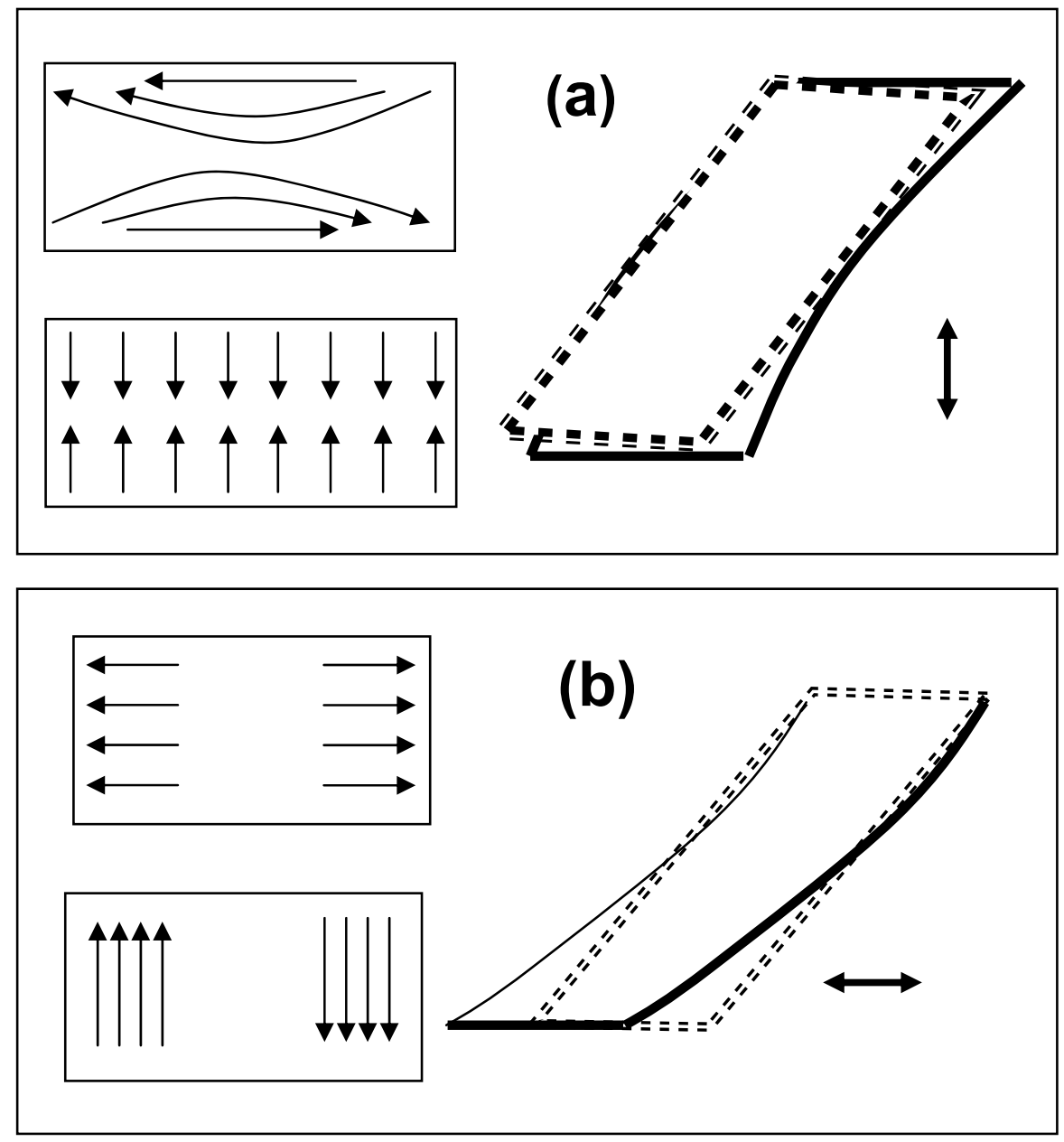

Figure 3: Electronic field lines associated with pure flexion modes. (a) and (b) are for flexion type 1 and flexion type 2 respectively 


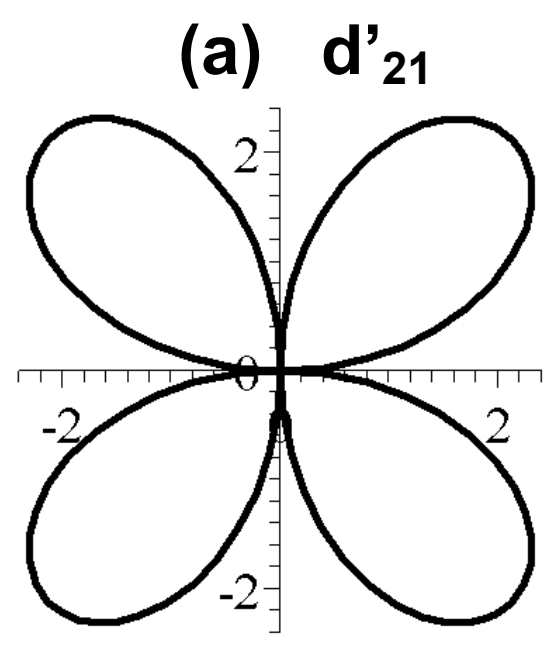

(b) $d^{\prime}{ }_{31}$

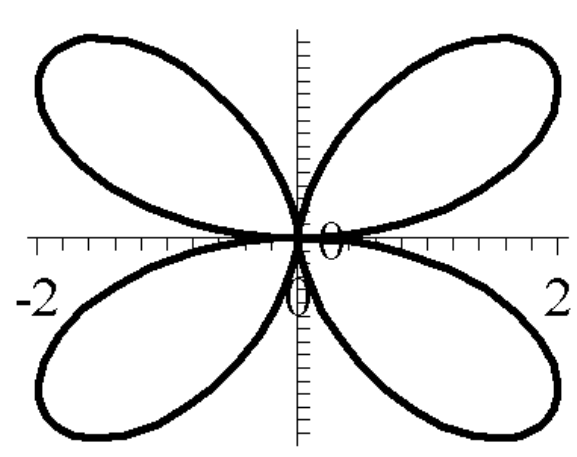

(c) $d^{\prime}{ }_{21}$

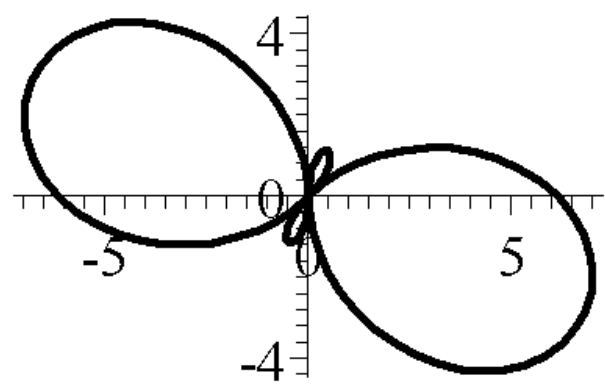

Figure 4: Polar plots of primed coefficients d ${ }_{21}$ and d ${ }_{31}\left(\times 10^{-12} \mathrm{~V} / \mathrm{m}\right)$. Plots (a) and (b) are for the $\mathrm{Y}$ cut. Plot (c) is for the $\mathrm{X}$ cut. 

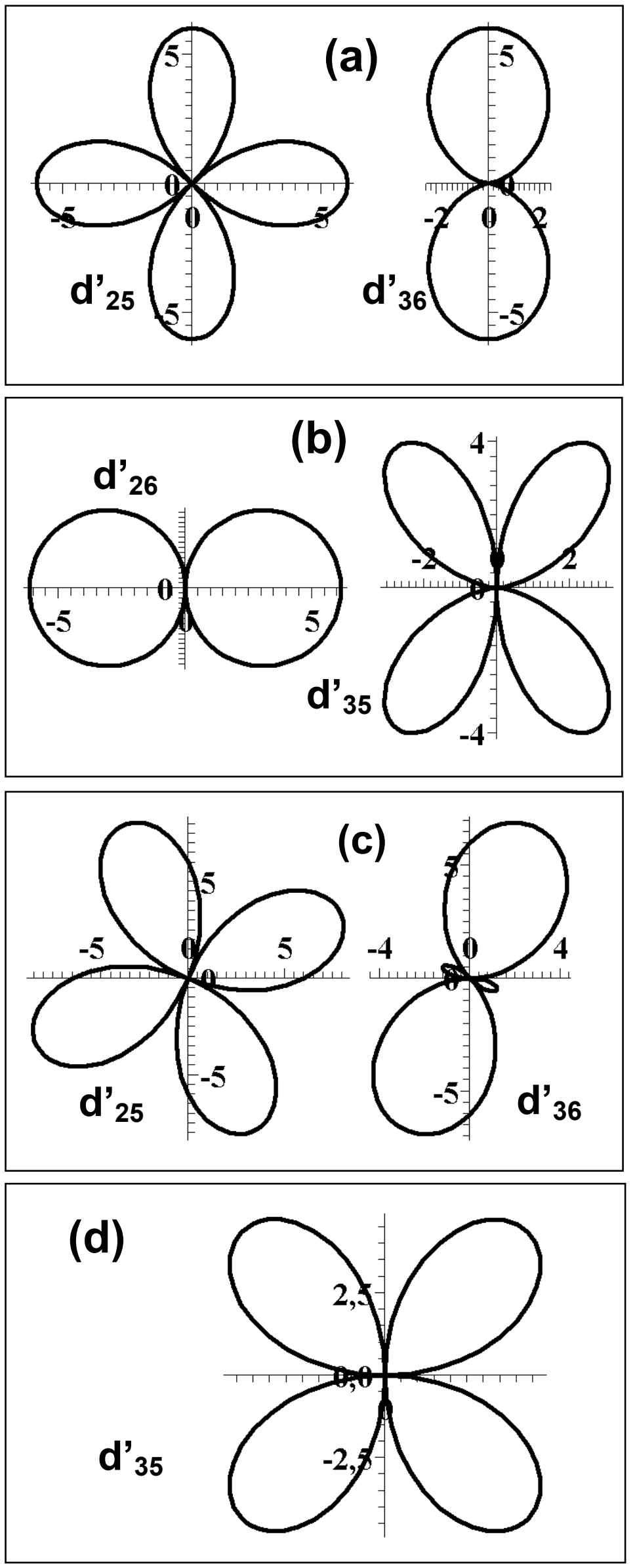

Figure 5: Polar plots of "shear coefficients". Graphs (a,b) and (c,d) are for the Y cut and the X cut respectively. 


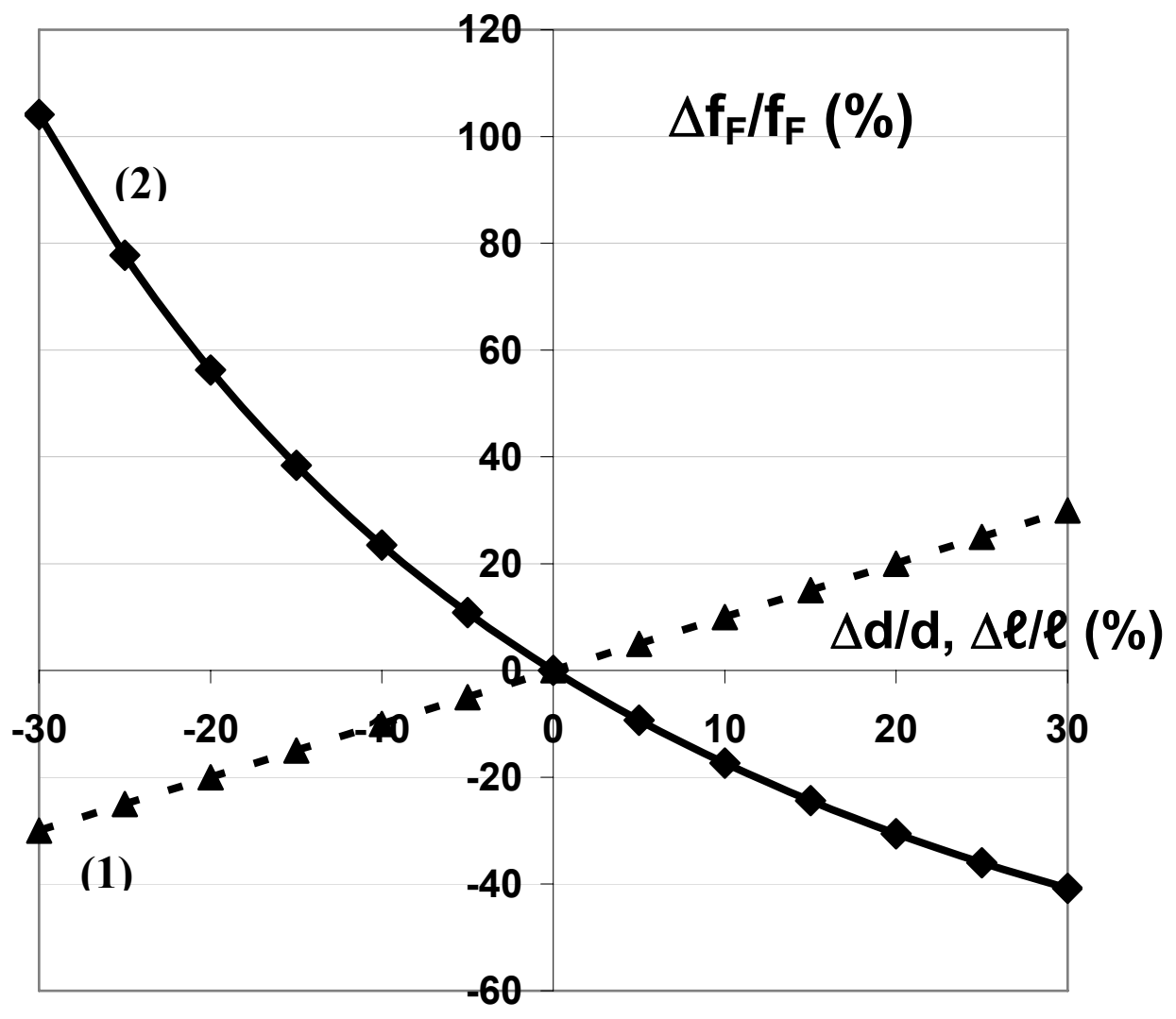

Figure 6: Relative changes in the resonant frequency $\mathrm{f}_{\mathrm{F}}$ with relative changes in thickness $\mathrm{d}$ (1) and in length $\ell$ (2) for an X cantilever vibrating in flexion mode type 1 . 


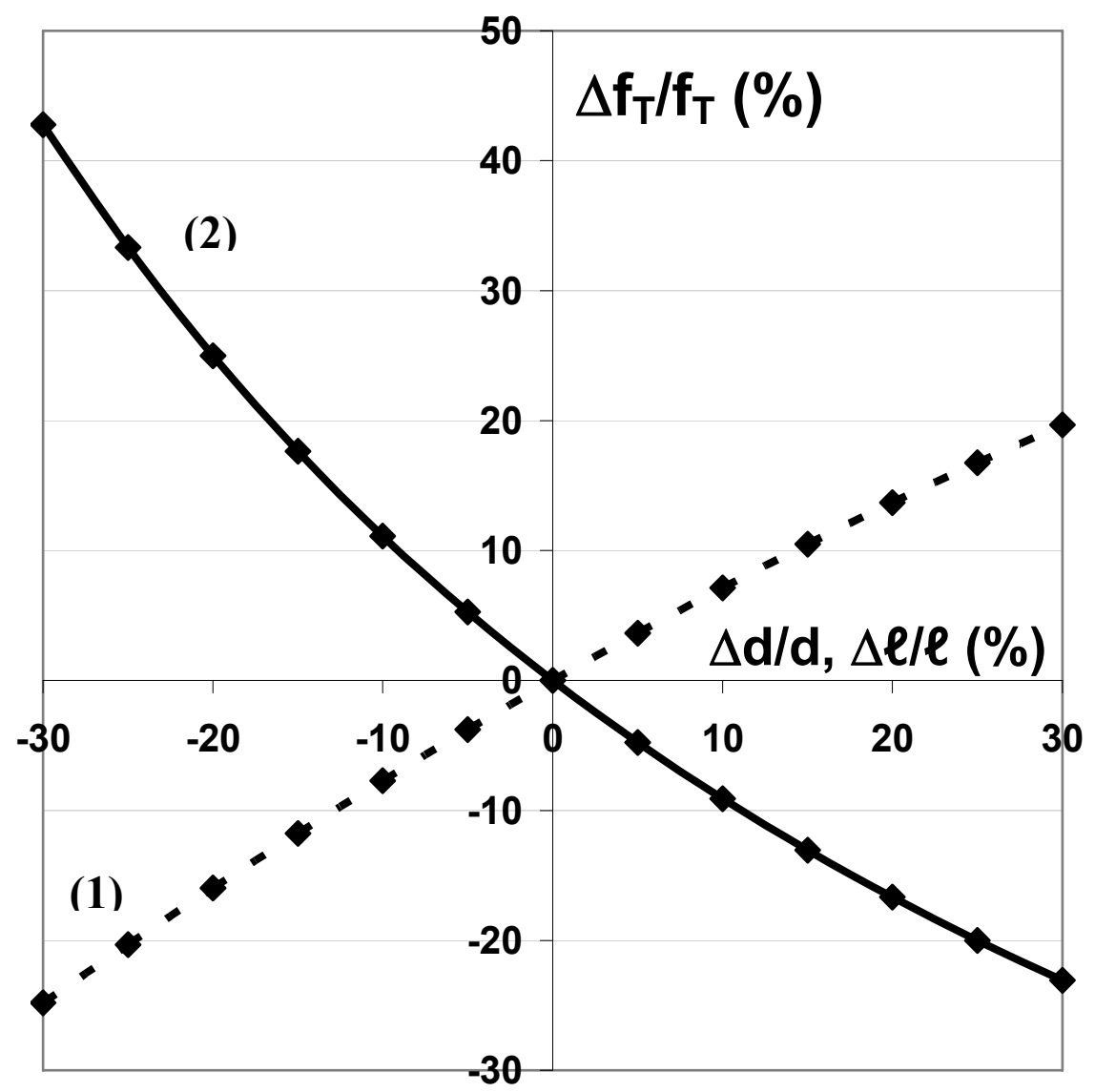

Figure 7: Relative changes in the resonant frequency $\mathrm{f}_{\mathrm{T}}$ with relative changes in thickness $\mathrm{d}$ (1) and in length $\ell$ (2) for a Y cantilever vibrating in torsion. 


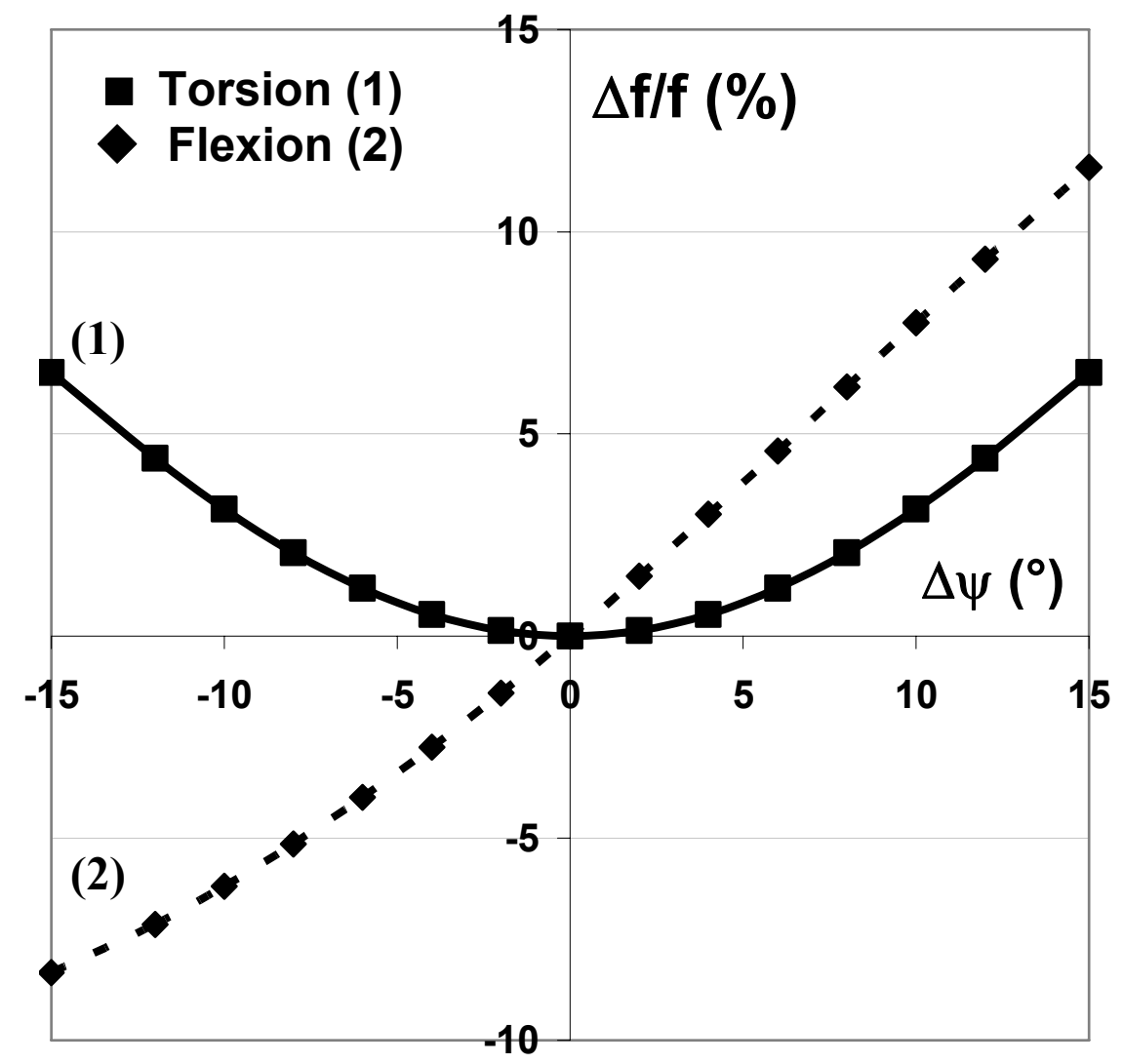

Figure 8: Relative changes in the resonance frequencies as a function of misalignment $\Delta \psi$. Curve (1) is for $\frac{\Delta f_{T}}{f_{T}}$ in the case of torsional mode. Curve (2) is for $\frac{\Delta f_{F}}{f_{F}}$ and for a flexion of type 1 . 


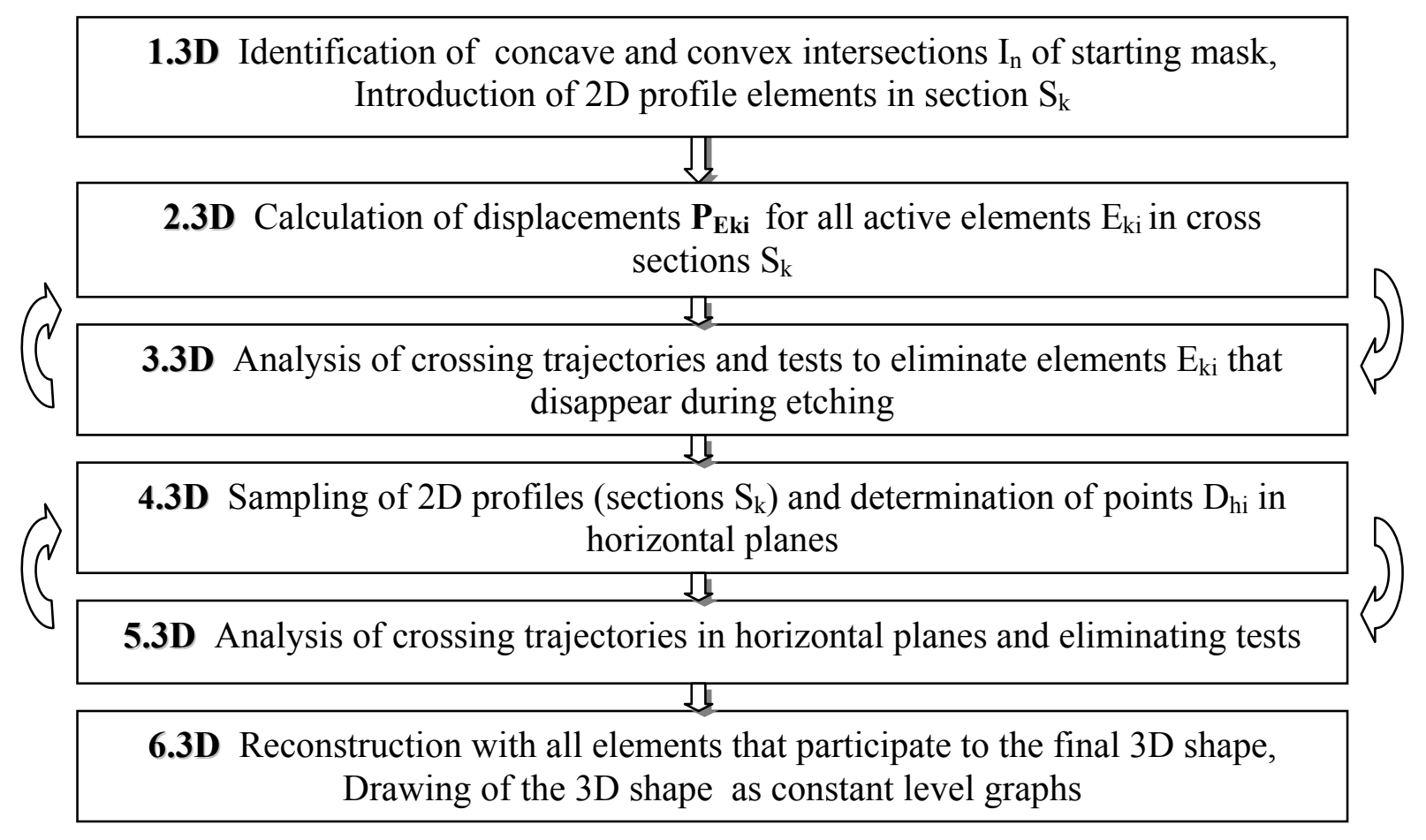

Figure 9: The flow chart of the self-elaborated simulator TENSOSIM 

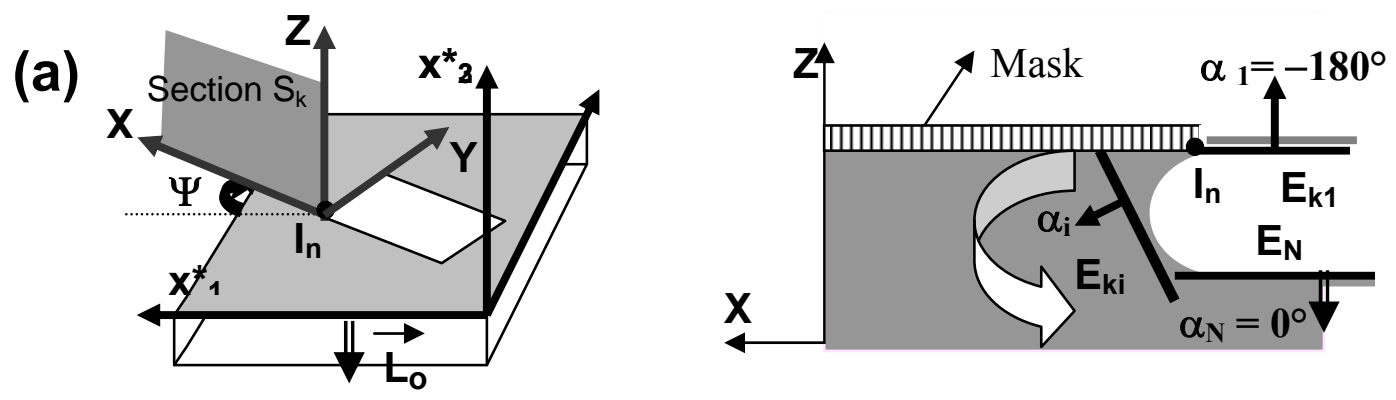

(b)

Figure 10: Geometry involved in step 1.3D. Identification of section in (a) and definition of angle $\alpha_{i}$ in (b) 

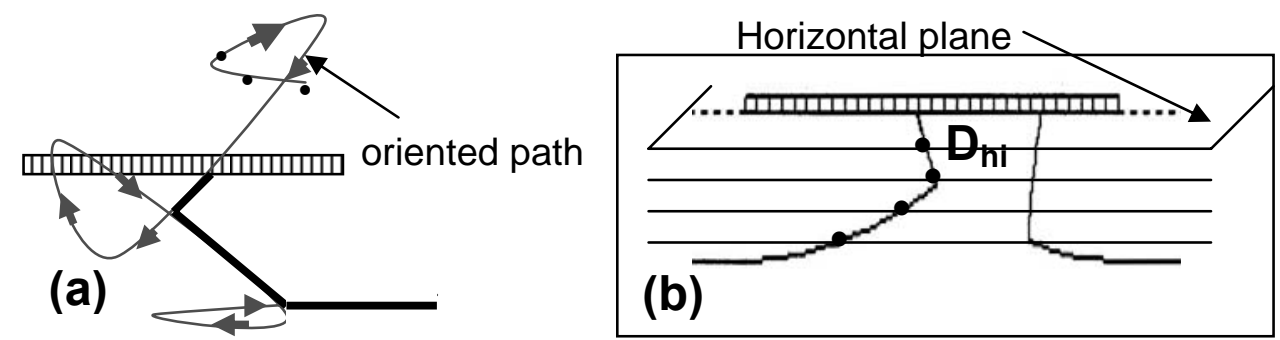

Figure 11: Crossing trajectories in section $\mathrm{S}_{\mathrm{k}}$ (a) and geometry involved in step 4.3D (b). 

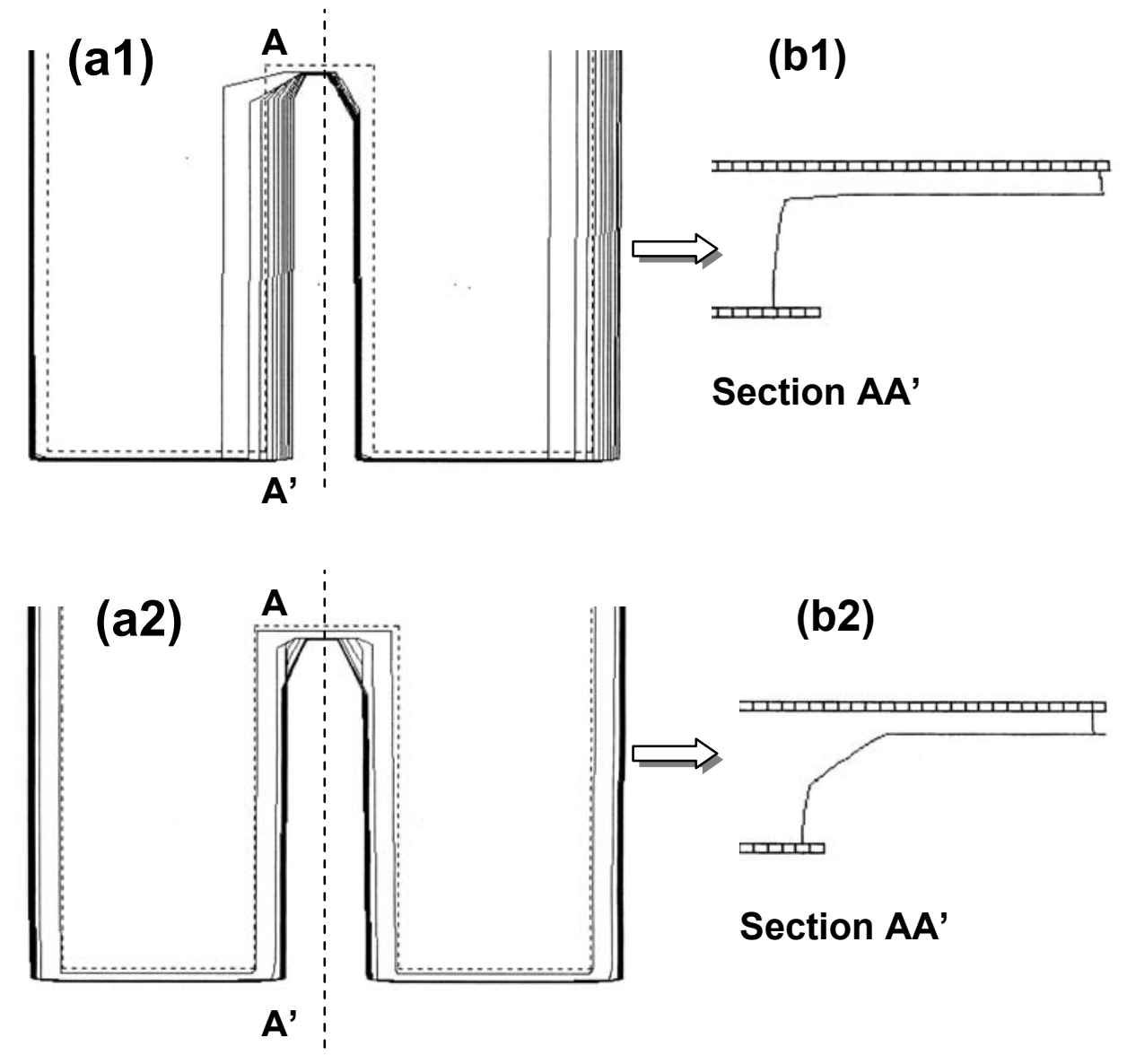

Figure 12: Simulations: $(\mathrm{a} 1, \mathrm{~b} 1)$ for cantilever etched on a $\mathrm{Y}$ cut $\left(\psi=180^{\circ}\right)$ and $(\mathrm{a} 2, \mathrm{~b} 2)$ on the face 1 of an $\mathrm{X}$ cut $\left(\psi=90^{\circ}\right)$ 


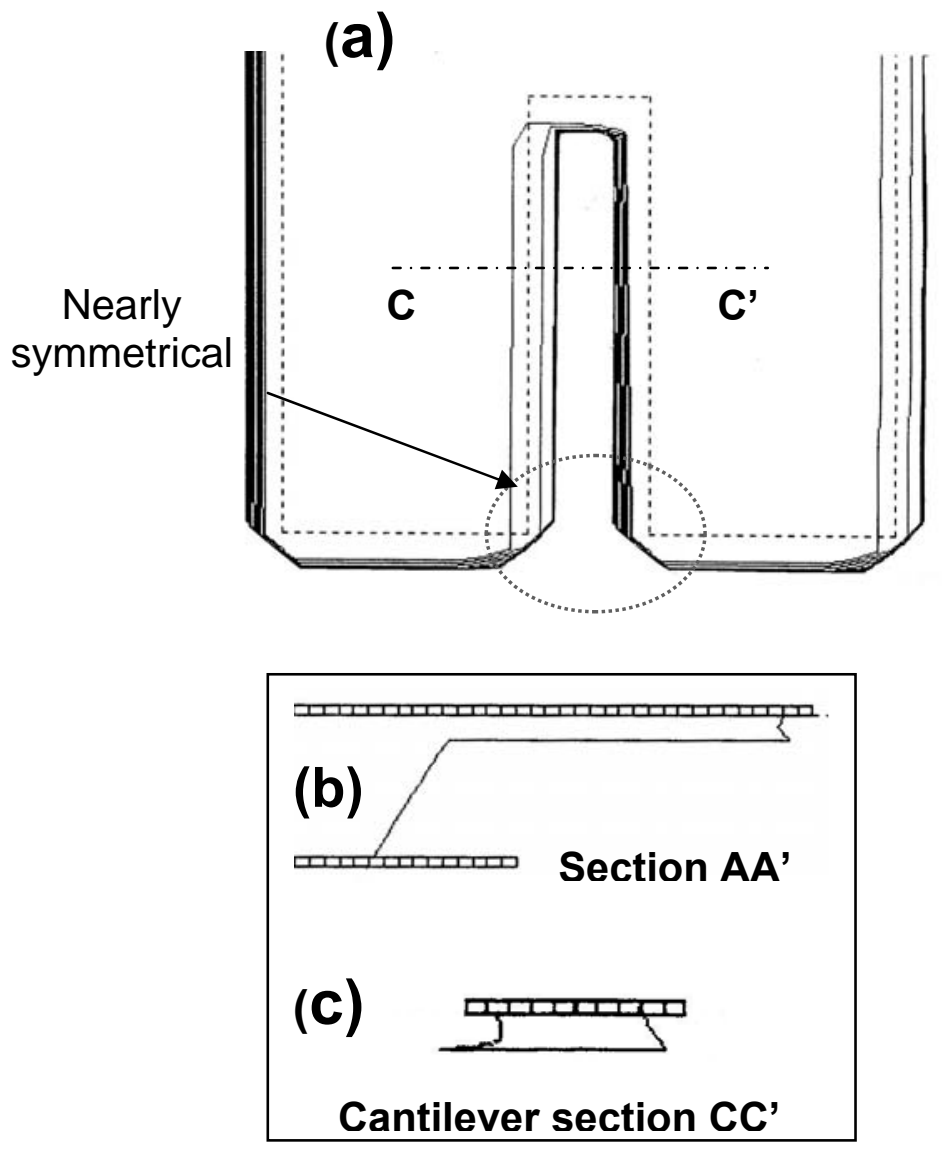

Figure 13: Simulations for a cantilever etched on a Y cut with alignment $\psi=225^{\circ}$ 

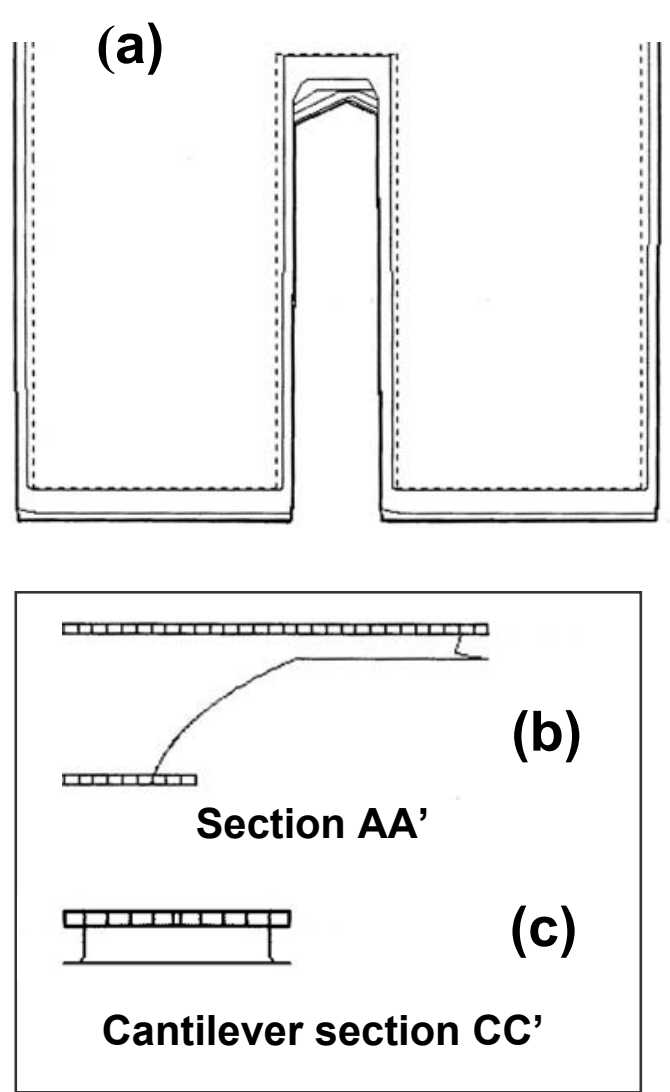

Figure 14: Simulations for the face 1 of an $\mathrm{X}$ cut and an alignment along $\mathrm{Y}$ axis $\left(\Psi=180^{\circ}\right)$ 

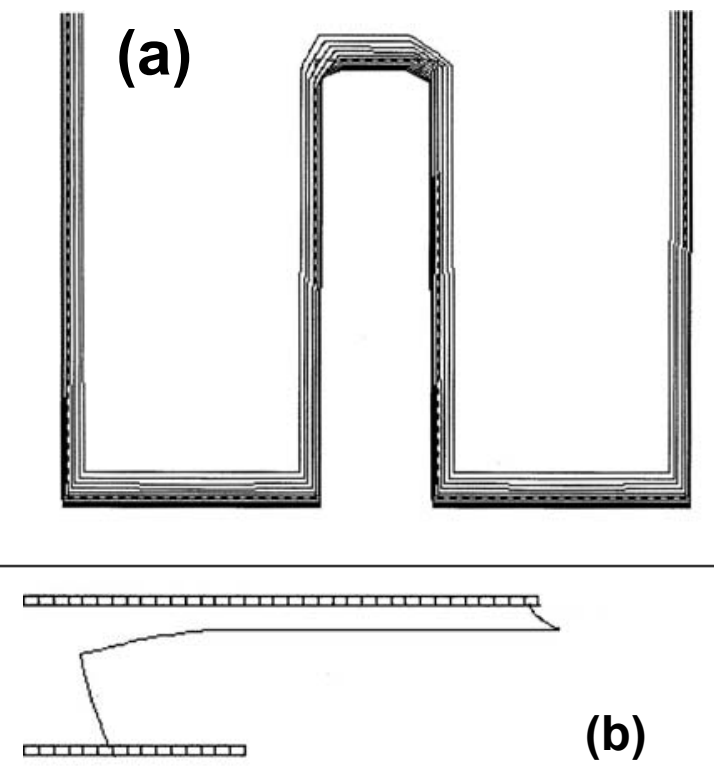

(b)

Section AA'

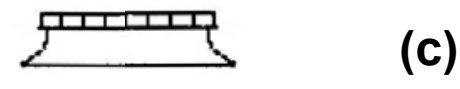

Cantilever section CC'

Figure 15: Simulations for the face 2 of an $\mathrm{X}$ cut and an alignment along $\mathrm{Y}$ axis ( $\left.\Psi=180^{\circ}\right)$ 


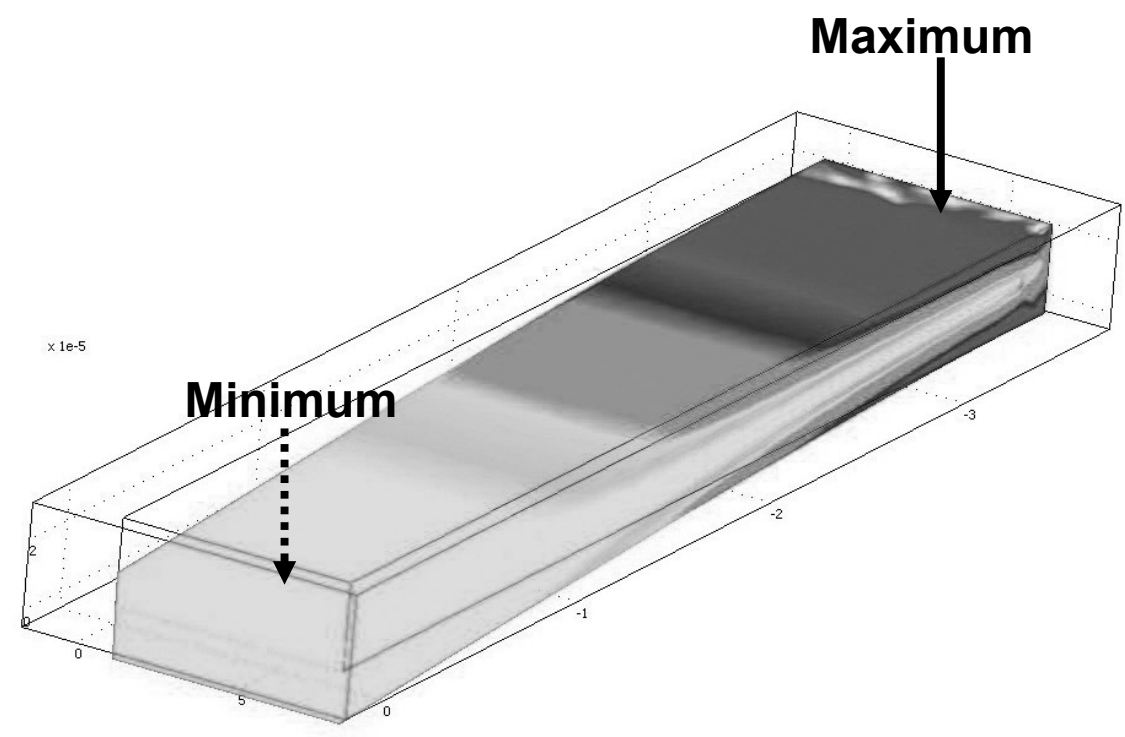

(a)
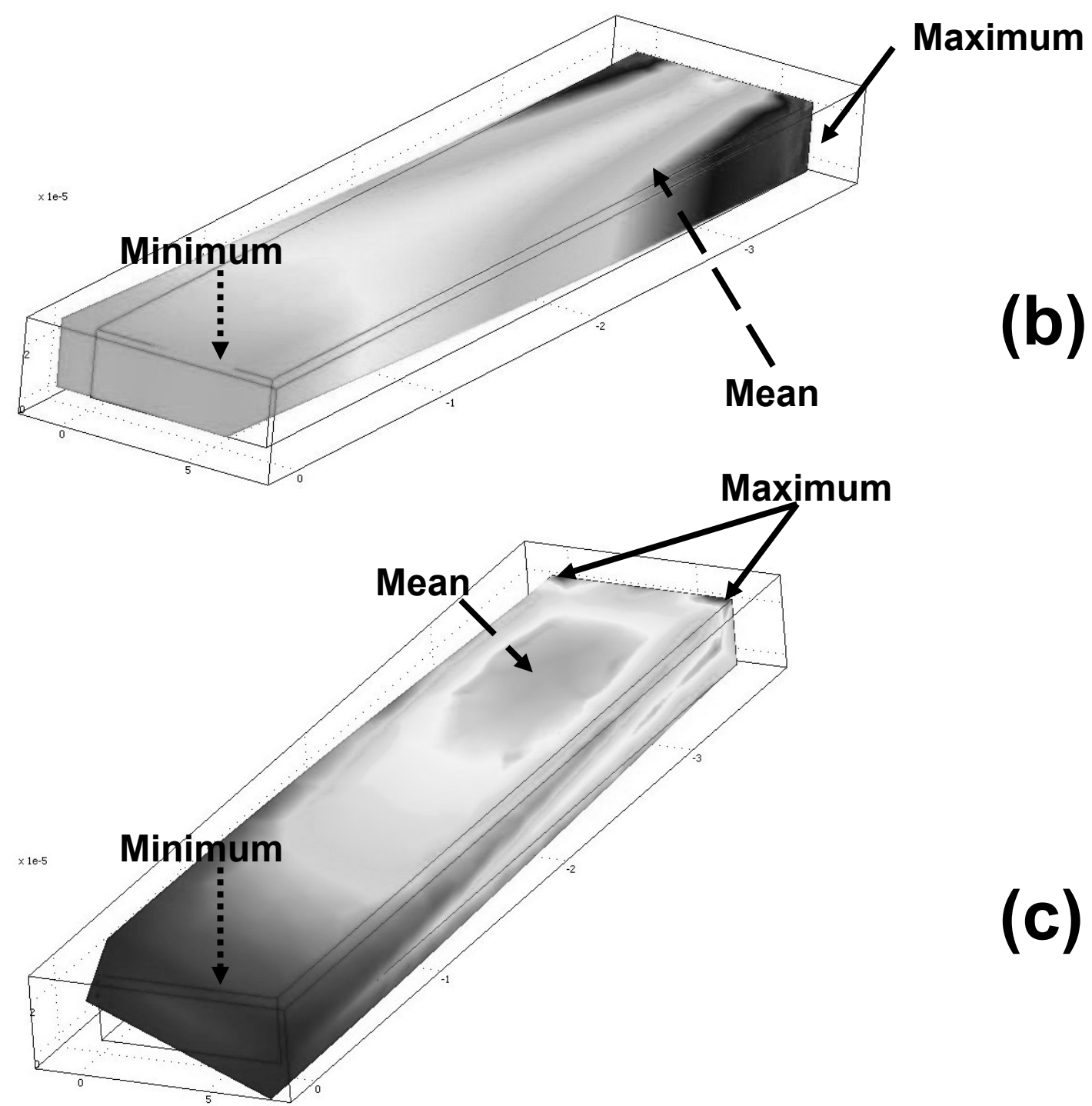

(c) 
Figure 16: Stress mappings as derived for cantilevers with mean dimensions as evaluated from simulations. Mappings (a), (b) and (c) are for the X cut and for flexion type 1, flexion type 2 and torsion modes respectively. Regions with maximum and minimum stresses are identified on graphs.
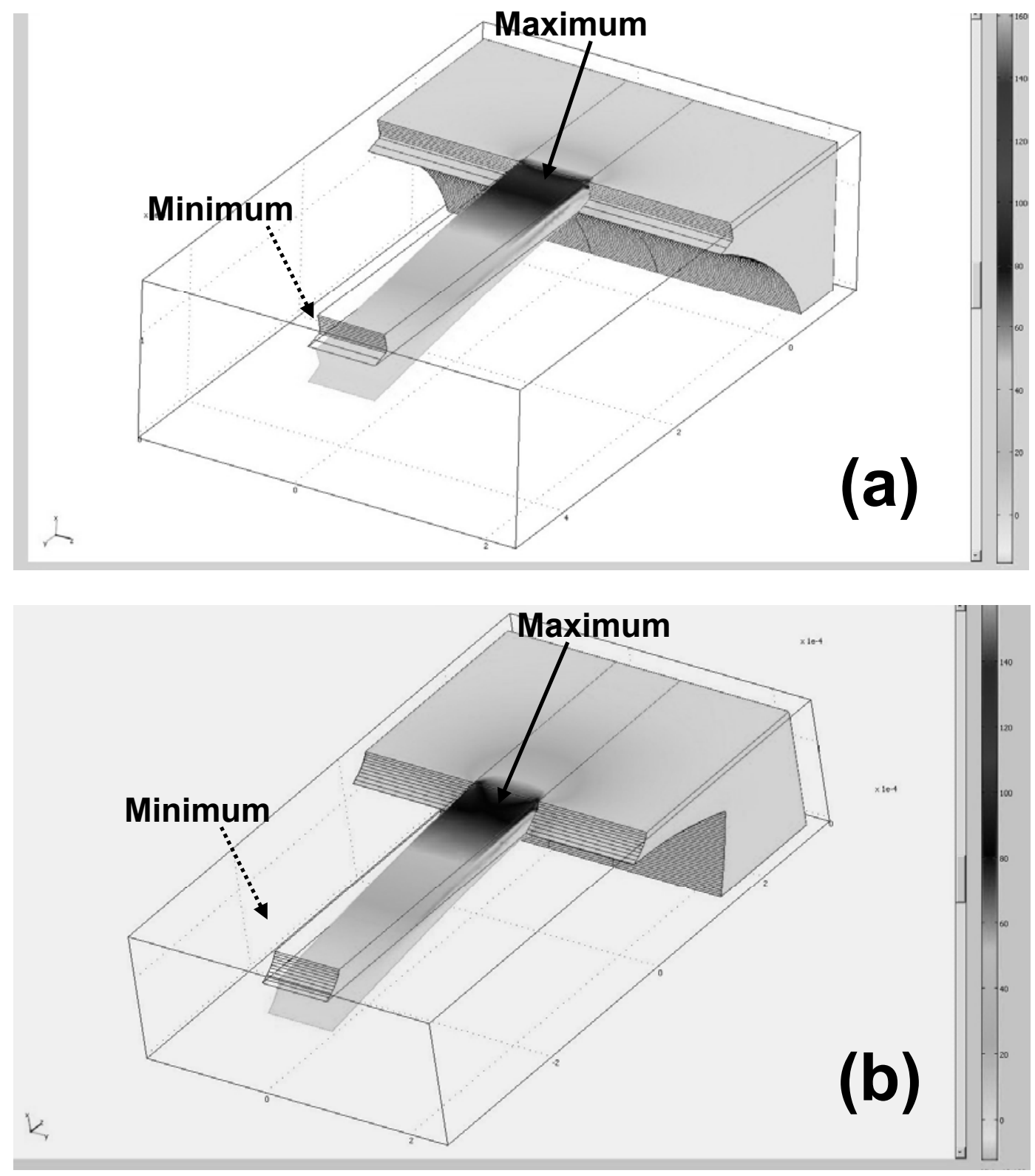

Figure 17: Stress mappings as derived for simulated X cantilevers. Mappings (a) and (b) are for the flexion type 1 and for faces 1 and 2 respectively. For convenience regions with maximum and minimum stresses are identified on graphs 


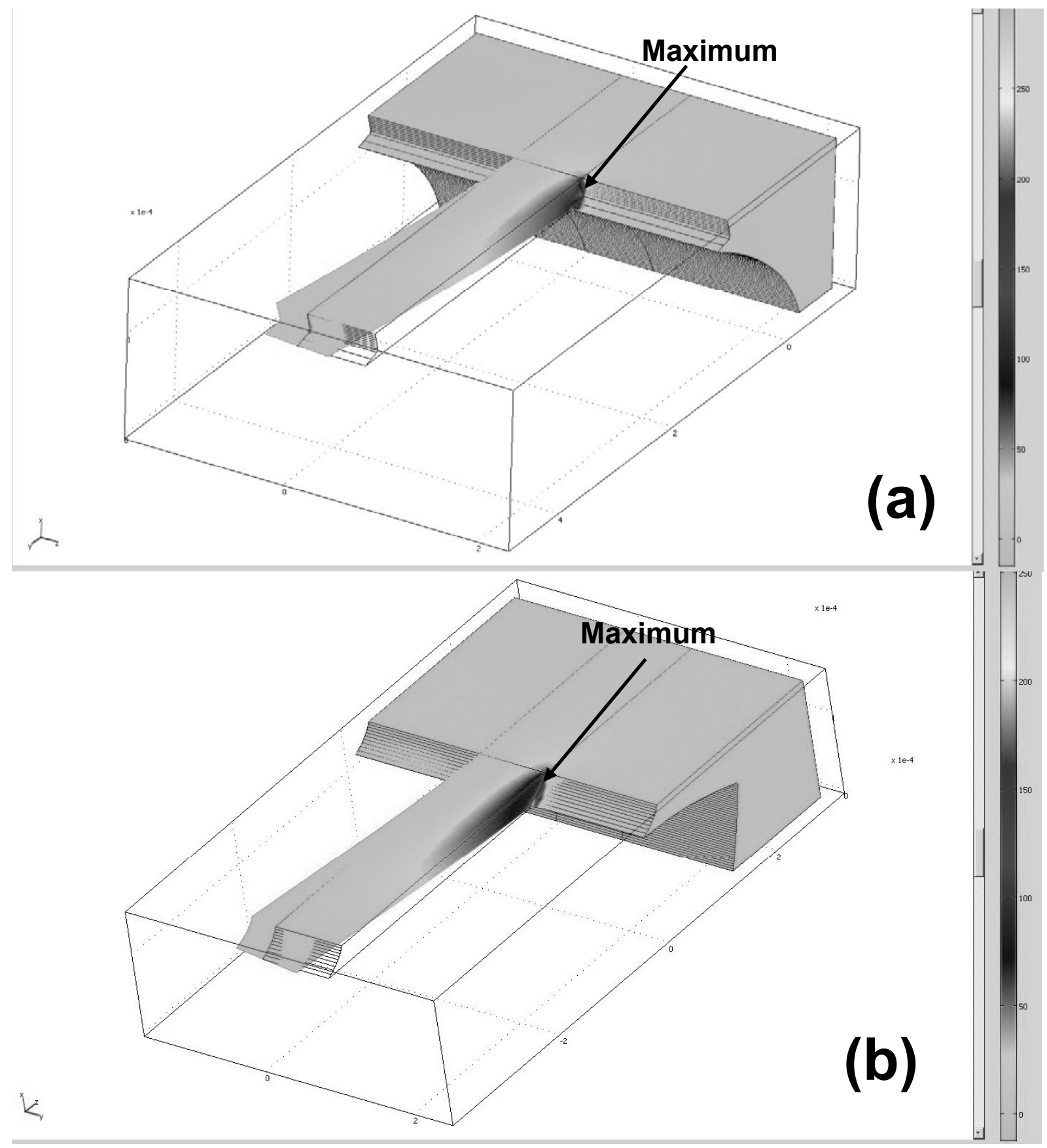

Figure 18: Stress mappings as derived for simulated X cantilevers. Mappings (a) and (b) are for the flexion type 2 and for faces 1 and 2 respectively. For convenience regions with maximum and minimum stresses are identified on graphs 


\begin{tabular}{|c|c|c|}
\hline Cut & $\varphi$ & $\theta$ \\
\hline $\mathrm{X}$ & $90^{\circ}$ & $0^{\circ}$ \\
\hline $\mathrm{Y}$ & $0^{\circ}$ & $0^{\circ}$ \\
\hline
\end{tabular}

Table 1: Reference values $\left(\varphi_{0}, \theta_{0}\right)$ for the angles of cuts of "commercial" $y$ - and $x$-cuts

\begin{tabular}{|c|c|c|c|}
\hline$\psi\left({ }^{\circ}\right)$ & Electrode configuration & Type of flexion & d' $_{21}$ \\
\hline 0,180 & A & Type 2 & $6.1510^{-12}$ \\
\hline 0,180 & B & Type 1 & $6.1510^{-12}$ \\
\hline
\end{tabular}

Table 2: Selection for the X cut: Alignment $\psi$, electrode configuration, type of flexion Corresponding primed coefficient $\mathrm{d}_{21}$ (in $\mathrm{V} / \mathrm{m}$ ).

\begin{tabular}{|c|c|c|c|c|c|c|}
\hline Cut & $\psi\left({ }^{\circ}\right)$ & Electrode configuration & $\mathrm{d}^{\prime}{ }_{25}$ & $\mathrm{~d}^{\prime}{ }_{36}$ & $\mathrm{~d}_{26}{ }_{26}$ & $\mathrm{~d}^{\prime}{ }_{35}$ \\
\hline $\mathrm{X}$ & 90,270 & $\mathrm{~B}$ & $6.0110^{-12}$ & $6.0110^{-12}$ & 0 & 0 \\
\hline $\mathrm{Y}$ & $45+\mathrm{n} 90$ & $\mathrm{~A}$ & 0 & $2.810^{-12}$ & $4.610^{-12}$ & $4.110^{-12}$ \\
\hline $\mathrm{Y}$ & 90,270 & $\mathrm{~B}$ & $6.0110^{-12}$ & $6.0110^{-12}$ & 0 & 0 \\
\hline
\end{tabular}


Table 3: Selected cuts, electrode configuration and corresponding primed shear coefficients (in $\mathrm{V} / \mathrm{m}$ ). $\mathrm{n}$ is a positive integer.

\begin{tabular}{|c|c|}
\hline Cut, $\psi$, Mode of vibration & Theory, case 1 \\
\hline X cut, $\psi=0^{\circ}, 180^{\circ}$, Flexion type 1 & .10185587 \\
\hline X cut, $\psi=0^{\circ}, 180^{\circ}$, Flexion type 2 & .2851964 \\
\hline X cut, $\psi=90^{\circ}, 270^{\circ}$, Torsion & 1.079256 \\
\hline Y cut $\psi=45^{\circ}+\mathrm{n} 90^{\circ}$, Torsion & 1.3141525 \\
\hline
\end{tabular}

Table 4: Values of the resonance frequencies (in $\mathrm{MHz}$ ) as computed from Eqs. 10 and 21 (Theory, case 1). Case 1 corresponds to the standard cantilever defined in section 3.3.

\begin{tabular}{|c|c|c|}
\hline Rank & Dissolution constants and relations & $v_{R}$ \\
\hline 7 & $\begin{array}{c}\mathrm{D}_{1(7)}=-(7 / 3) \mathrm{D}_{1(1) 2(6)}=-7 \mathrm{D}_{1(3) 2(4)}=-21 \mathrm{D}_{1(5) 2(2)}, \mathrm{D}_{1(3) 3(4)}=-\mathrm{D}_{1(1) 2(2) 3(4)} \\
\mathrm{D}_{1(5) 3(2)}=-5 \mathrm{D}_{1(3) 2(2) 3(2)}=-(5 / 3) \mathrm{D}_{1(1) 2(4) 3(2),} \\
\mathrm{D}_{1(5) 2(1) 3(1)}=-\mathrm{D}_{1(3) 2(3) 3(1)}=\mathrm{D}_{1(1) 2(5) 3(1)}\end{array}$ & 4 \\
\hline 8 & $\begin{array}{c}\mathrm{D}_{1(8)}=\mathrm{D}_{2(8)}=7 \mathrm{D}_{1(6) 2(2)}=(35 / 3) \mathrm{D}_{1(4) 2(4)}=7 \mathrm{D}_{1(2) 2(6)} \\
\mathrm{D}_{1(6) 2(1) 3(1)}=3 \mathrm{D}_{1(4) 2(3) 3(1)}=9 \mathrm{D}_{1(2) 2(5) 3(1)}=-(3 / 7) \mathrm{D}_{2(7) 3(1)} \\
\mathrm{D}_{1(6) 3(2)}=\mathrm{D}_{2(6) 3(2)}=5 \mathrm{D}_{1(2) 2(4) 3(2)}=5 \mathrm{D}_{1(4) 2(2) 3(2)} \\
\mathrm{D}_{1(4) 2(1) 3(3)}=3 \mathrm{D}_{1(2) 2(3) 3(3)}=-(3 / 5) \mathrm{D}_{2(5) 3(3)} \\
\mathrm{D}_{1(4) 3(4)}=\mathrm{D}_{2(4) 3(4)}=3 \mathrm{D}_{1(2) 2(2) 3(4)} \\
\mathrm{D}_{1(2) 2(1) 3(5)}=-\mathrm{D}_{2(3) 3(5)}, \mathrm{D}_{1(2) 3(6)}=\mathrm{D}_{2(2) 3(6)}, \quad \mathrm{D}_{3(8)}\end{array}$ & 8 \\
\hline 9 & $\begin{array}{c}\mathrm{D}_{1(9)}=\mathrm{D}_{1(1) 2(8)}=-\mathrm{D}_{1(7) 2(2)}=\mathrm{D}_{1(5) 2(4)}=\mathrm{D}_{1(3) 2(6)} \\
\mathrm{D}_{1(7) 2(1) 3(1)}=-3 \mathrm{D}_{1(5) 2(3) 3(1)}=-3 \mathrm{D}_{1(3) 2(5) 3(1)}=\mathrm{D}_{1(1) 2(7) 3(1)} \\
\mathrm{D}_{1(7) 3(2)}=-21 \mathrm{D}_{1(5) 2(2) 3(2)}=-7 \mathrm{D}_{1(3) 2(4) 3(2)}=-(7 / 3) \mathrm{D}_{1(1) 2(6) 3(2)} \\
\mathrm{D}_{1(5) 2(1) 3(3)}=-\mathrm{D}_{1(3) 2(3) 3(3)}=\mathrm{D}_{1(1) 2(5) 3(3)} \\
\mathrm{D}_{1(5) 3(4)}=-5 \mathrm{D}_{1(3) 2(2) 3(4)}=-(5 / 3) \mathrm{D}_{1(1) 2(4) 3(4)}, \quad \mathrm{D}_{1(3) 3(6)}=-\mathrm{D}_{1(1) 2(2) 3(6)}\end{array}$ & 6 \\
\hline 10 & $\begin{array}{c}\mathrm{D}_{1(10)}=\mathrm{D}_{2(10)}=9 \mathrm{D}_{1(8) 2(2)}=21 \mathrm{D}_{1(6) 2(4)}=21 \mathrm{D}_{1(4) 2(6)}=9 \mathrm{D}_{1(2) 2(8)} \\
\mathrm{D}_{1(8) 2(1) 3(1)}=-\mathrm{D}_{1(6) 2(3) 3(1)}=\mathrm{D}_{1(4) 2(5) 3(1)}=-\mathrm{D}_{1(2) 2(7) 3(1)}=\mathrm{D}_{2(8) 3(1)} \\
\mathrm{D}_{1(8) 3(2)}=7 \mathrm{D}_{1(2) 2(6) 3(2)}, \quad \mathrm{D}_{1(4) 2(3) 3(3)}=3 \mathrm{D}_{1(2) 2(5) 3(3)} \\
\mathrm{D}_{1(6) 3(4)}=\mathrm{D}_{2(6) 3(4)}=5 \mathrm{D}_{1(4) 2(2) 3(4)}=5 \mathrm{D}_{1(2) 2(4) 3(4)} \\
\mathrm{D}_{1(4) 2(1) 3(5)}=3 \mathrm{D}_{1(2) 2(3) 3(5)}=-(3 / 5) \mathrm{D}_{2(5) 3(5)} \\
\mathrm{D}_{1(4) 3(6)}=\mathrm{D}_{2(4) 3(6)}=3 \mathrm{D}_{1(2) 2(2) 3(6)} \\
\mathrm{D}_{1(2) 2(1) 3(7)}=-\mathrm{D}_{2(3) 3(7)}, \mathrm{D}_{1(2) 3(8)}=\mathrm{D}_{2(2) 3(8)}, \quad \mathrm{D}_{3(10)}\end{array}$ & 10 \\
\hline
\end{tabular}

Table 5: Relations between non-zero constants and number $v_{R}$ of independent constants. 
In this table we adopt the notation $\mathrm{D}_{1\left(\mathrm{~N}_{1}\right) 2\left(\mathrm{~N}_{2}\right) 3\left(\mathrm{~N}_{3}\right)}$ where $\mathrm{N}_{1}, \mathrm{~N}_{2}$ and $\mathrm{N}_{3}$ are the number of subscripts 1, 2 and 3 respectively. Note that $\mathrm{N}_{1}+\mathrm{N}_{2}+\mathrm{N}_{3}$ is equal to the tensor rank $\mathrm{R}$.

\begin{tabular}{|c|c|c|}
\hline Cut, Face, $\psi$, Mode of vibration & Theory, case 2 & FEM, case 2 \\
\hline X cut, face $1, \psi=0^{\circ}, 180^{\circ}$, Flexion type 1 & .137109 & .1381535 \\
\hline X cut, face $2, \psi=0^{\circ}, 180^{\circ}$, Flexion type 1 & .0907172 & .090963 \\
\hline X , face $1, \psi=0^{\circ}, 180^{\circ}$, Flexion type 2 & .38391 & .3770983 \\
\hline X cut, face $2 \psi=0^{\circ}, 180^{\circ}$, Flexion type 2 & .322953 & .3134445 \\
\hline X cut, face $1, \psi=90^{\circ}$, Torsion & 1.25217 & - \\
\hline X cut, face $2, \psi=90^{\circ}$, Torsion & 0.73213 & - \\
\hline
\end{tabular}

Table 6: Values of the resonance frequencies (in MHz) as computed from Eqs. 10 and 21 (Theoretical, case 2) and as evaluated from FEM analysis. Case 2 is for an X cantilever with vertical walls but with mean length and width as derived from simulations of etching shapes.

\begin{tabular}{|c|c|c|c|}
\hline Cut & $\psi\left({ }^{\circ}\right)$ & Flexion type 1 & Flexion type 2 \\
\hline $\mathrm{X}$ face 1 & 180 & $\Delta \mathrm{f}_{\mathrm{F} 1} / \mathrm{f}_{\mathrm{F} 1} \approx-4.5 \%$ & $\Delta \mathrm{f}_{\mathrm{F} 2} / \mathrm{f}_{\mathrm{F} 2} \approx-9.5 \%$ \\
\hline $\mathrm{X}$ face 2 & 180 & $\Delta \mathrm{f}_{\mathrm{F} 1} / \mathrm{f}_{\mathrm{F} 1} \approx 46 \%$ & $\Delta \mathrm{f}_{\mathrm{F} 2} / \mathrm{f}_{\mathrm{F} 2} \approx 50 \%$ \\
\hline
\end{tabular}

Table 7: Frequency shifts for the two types of flexion. 